\title{
The Current Status of Meat Processing Facilities in Agricultural Education Programs in West Virginia
}

\author{
Eleanor Nicole Porter \\ West Virginia University
}

Follow this and additional works at: https://researchrepository.wvu.edu/etd

\section{Recommended Citation}

Porter, Eleanor Nicole, "The Current Status of Meat Processing Facilities in Agricultural Education Programs in West Virginia" (2014). Graduate Theses, Dissertations, and Problem Reports. 614. https://researchrepository.wvu.edu/etd/614

This Thesis is protected by copyright and/or related rights. It has been brought to you by the The Research Repository @ WVU with permission from the rights-holder(s). You are free to use this Thesis in any way that is permitted by the copyright and related rights legislation that applies to your use. For other uses you must obtain permission from the rights-holder(s) directly, unless additional rights are indicated by a Creative Commons license in the record and/ or on the work itself. This Thesis has been accepted for inclusion in WVU Graduate Theses, Dissertations, and Problem Reports collection by an authorized administrator of The Research Repository @ WVU. For more information, please contact researchrepository@mail.wvu.edu. 
The Current Status of Meat Processing Facilities in

Agricultural Education Programs

in West Virginia

Eleanor Nicole Porter

Thesis submitted to the

Davis College of Agriculture, Natural Resources and Design

at West Virginia University

in partial fulfillment of the requirements

for the degree of

Master of Science
in
Agricultural and Extension Education

Harry N. Boone, Jr., Ph.D., Chair

P. Brett Kenney, Ph. D.

Stacy A. Gartin, Ph.D.

Deborah A. Boone, Ph.D.

Division of Resource Management

Morgantown, West Virginia

2014

Keywords: Agricultural Education, Agriculture, Education, Animal Processing, Meat Processing, Meat Processing Facilities, Professional Development 


\author{
ABSTRACT \\ The Current Status of Meat Processing Facilities in \\ Agricultural Education Programs \\ in West Virginia
}

Eleanor Nicole Porter

West Virginia has become a model for the local food movement. With a push for more locally grown food, there is a need for more people to provide local agricultural services. A number of agricultural education programs in West Virginia are providing students with hands on training in the meat processing field. Currently there is little information on the knowledge and skill level of instructors operating high school meats processing facilities. Therefore, this study was conducted to determine the expertise of the instructors and to determine the training needs of these individuals in the area of meat processing. The purpose of this study was to determine the meat processing facilities and equipment that are being used by agricultural education programs along with the professional development needs of the teachers in this area. The study was limited to the 103 agricultural education teachers employed in West Virginia during the 2013-2014 school year. Fifty-eight teachers (56.31\%) responded to the survey. The results of the study included: a low number of educators teaching animal processing, lack of funds to start meat processing programs, a high interest to teach animal processing among those who do not already teach the subject matter, students gained skills and experience in meats processing, and a low percentage of graduates securing employment in this area. 


\section{ACKNOWLEDGEMENTS}

The professors on my graduate committee are wonderful teachers who have motivated me in a lot of different ways. Dr. Harry Boone has guided me through my research for the last two years, while becoming a positive role model for me. He is a person I turn to when trying to make career and life choices. Over the last few years I have found him to be the man with the answers and a friend. Dr. Deborah Boone is a lady that I like to think of as "Mama Deb". She is always there for her students with wisdom and care. She has helped me a lot through my five years of college. Dr. Stacy Gartin has always pushed me to do more. He has great expectations from his students and a wonderful sense of humor. He has helped me to become more creative in my education. Dr. Brett Kenney is a very intelligent man who taught me so much about animal processing and meat science. He is also the person that inspired me to research this specific topic. I would like to thank all of them for their brilliant abilities and characteristics and for giving up the time to help guide me in this research.

I would like to give a special thank you to all the agricultural education teachers in the state for taking the time to fill out my survey and provide useful responses for my study.

I would like to thank my parents, Reid and Susan Porter, for always supporting the decisions that I make. They are the two people that I know I can always count on. I know I could not have completed this without their love and endless support.

I would also like to thank Jim Workman, my former agricultural education teacher. He has always been such an inspiration to me. He is a great, knowledgeable teacher who is always there to help his students. I cannot thank him enough for the guidance and knowledge he gave me in this research and in life.

Finally, I would like to thank all my friends who have helped me along the way, especially those who have had to listen to me complain for the last two years and have encouraged and motivated me to complete my research. 


\section{TABLE OF CONTENTS}

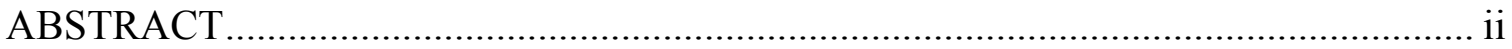

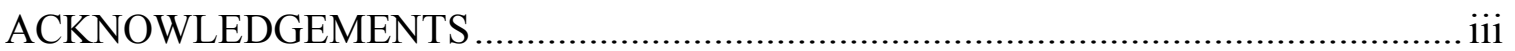

LIST OF TABLES .......................................................................................... vi

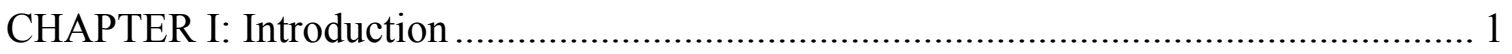

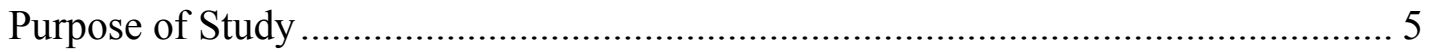

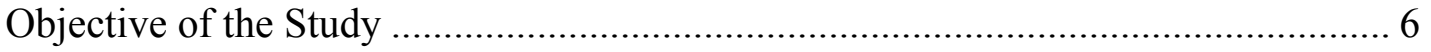

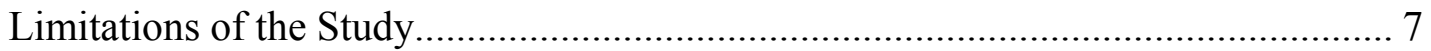

CHAPTER II: Review of Literature .................................................................... 8

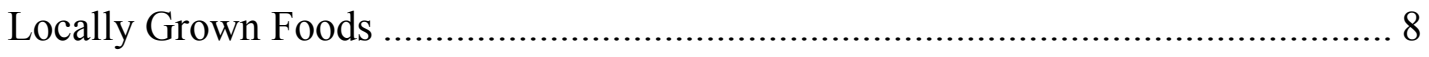

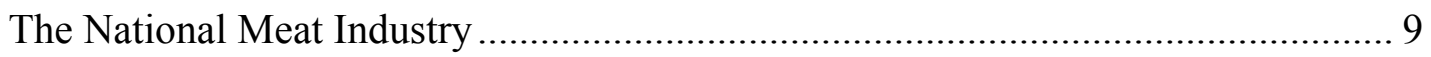

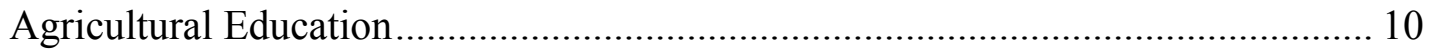

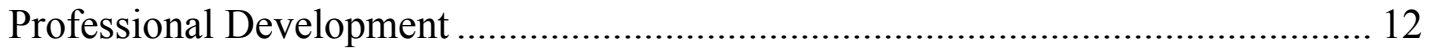

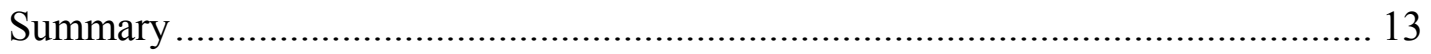

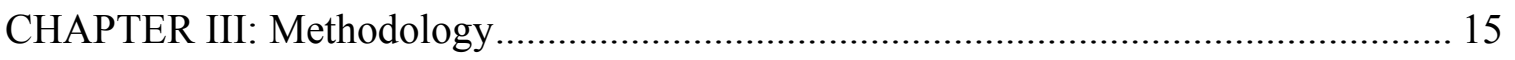

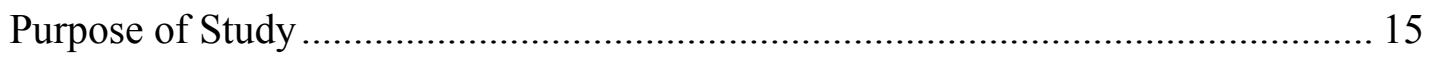

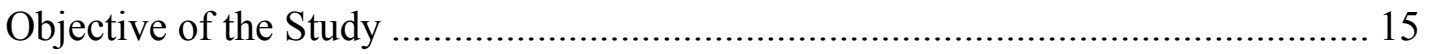

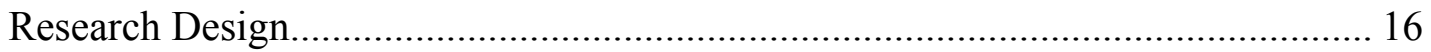

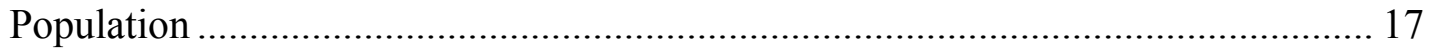

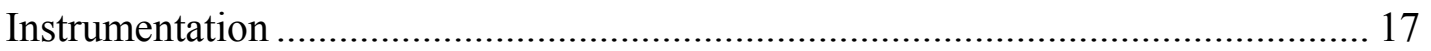

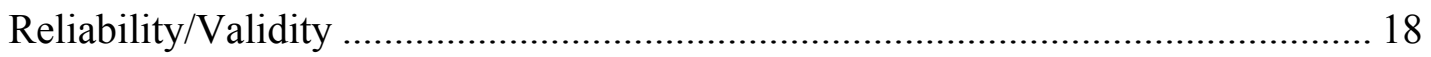

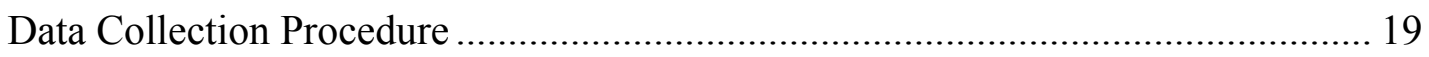

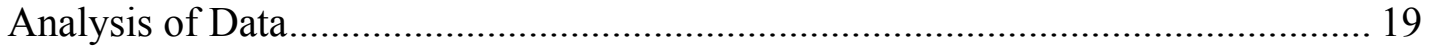

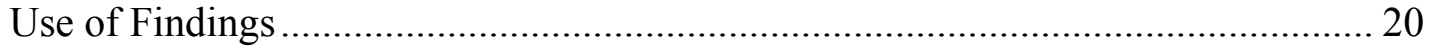

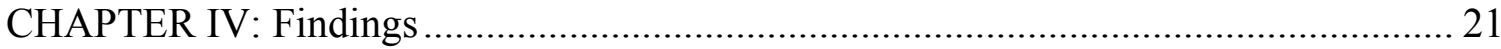

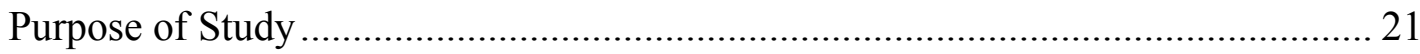

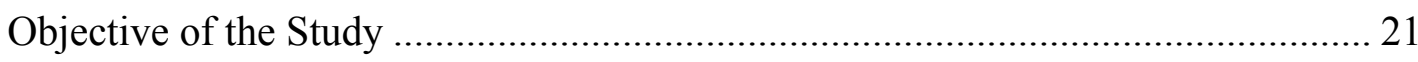

Agricultural Educators who Teach Animal Processing ........................................ 22

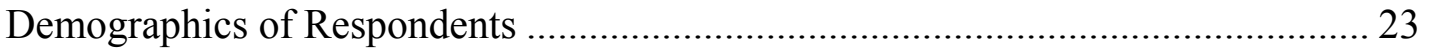

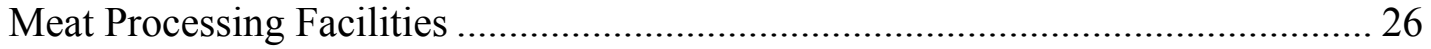

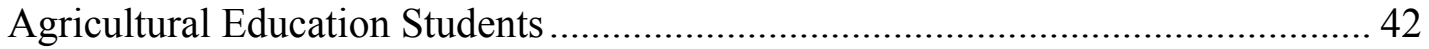

Agriculture Teachers who do not Teach Animal Processing................................ 58 
Agricultural Education Teachers who do not have a Meat Processing Facility ....... 60

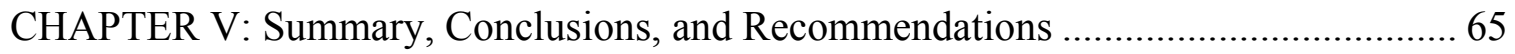

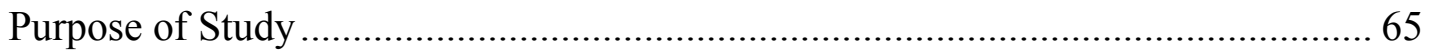

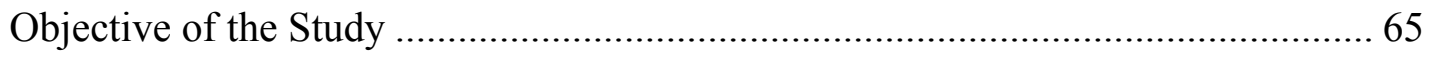

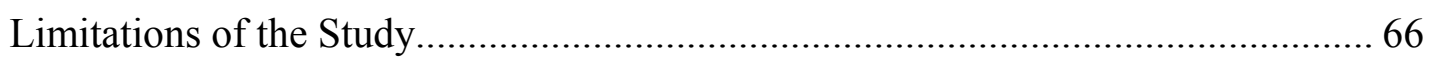

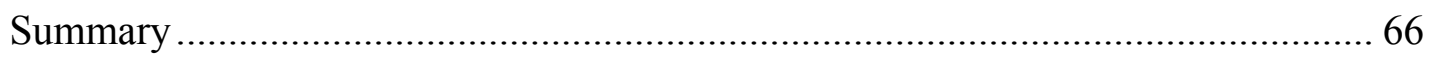

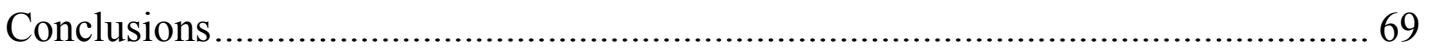

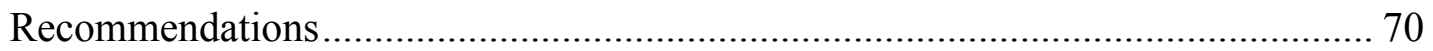

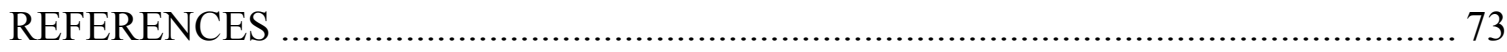

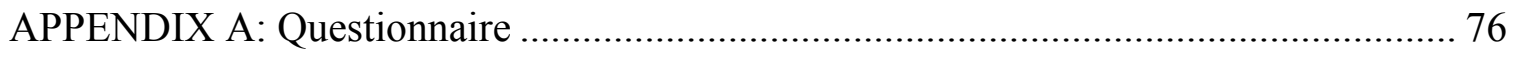

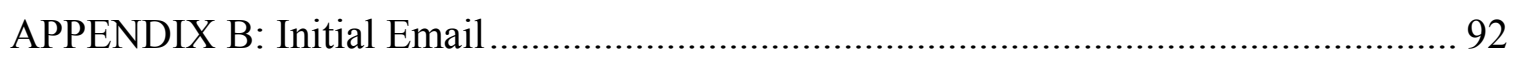

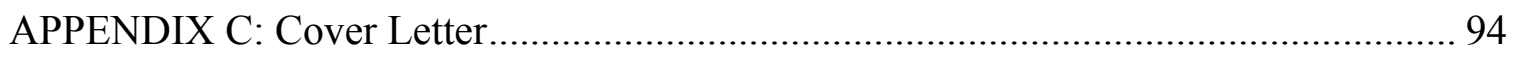

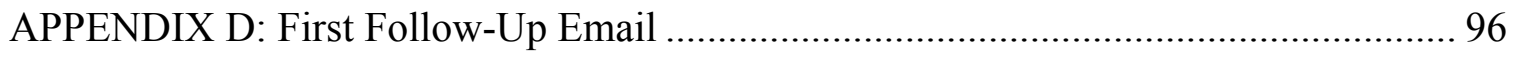

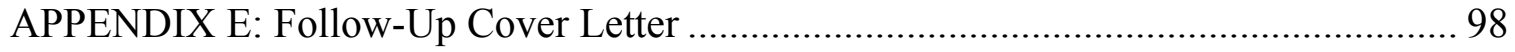

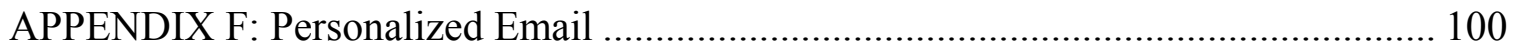

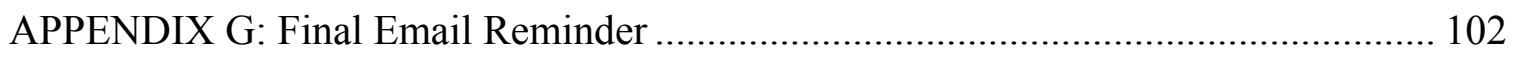

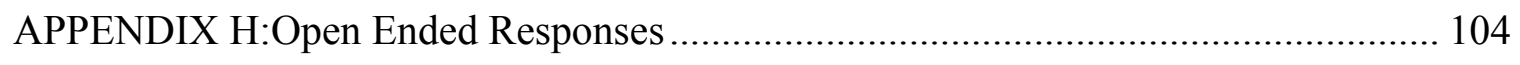

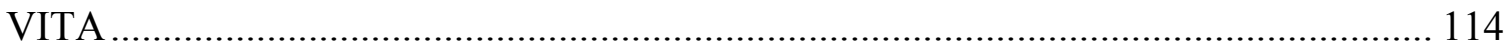




\section{LIST OF TABLES}

Table Title

Page

1 Agricultural Educators Who Teach Animal Processing

2 Agricultural Educators Who Teach Animal Processing and Had Access to a Meat Facility .23

3 Gender of Agricultural Educators .23

4 Age of Agricultural Educators .24

Years of Teaching Experience. .25

6

Highest Level of Education of Agricultural Education Teachers ........................25

8 Number of Teachers in Agricultural Education Program and who use Meat Facility

9 Meat Processing Equipment that was Purchased New, Purchased Used, or Donated.....

10 Square Footage of the Floor Space of the Facility, Cooler, and Freezer ..... .34

11 Number of Chest or Upright Freezers used for Meat Processing .34

12 Funding for Meat Processing Facility.... .35

13 Funding for the Day-to-Day Operation of the Meat Processing Facility..... .36

14 Number of Animals Processed on Average during a School Year .......................37

15 Number of Days Agricultural Educators use Meat Processing Facilities. .38

16 Number of Meat Processing Facilities with a Custom or Commercial License .38

17 Number of Agricultural Educators who Plan to Obtain a Commercial License .39

18 Groups that Worked Cooperatively Within the Meat Processing Program..... 40

19 Agricultural Education Programs who Supply Meat to Local Places .40

20 Value Added Processing Techniques Implemented by Agricultural Educators.

21 Jobs Available in the Agricultural Educator's Local Area .42

22 Number of Students who Exhibit Hams and Bacons

23 Number of Student in the Program, Using the Facility, and Finding Employment 
24 Number of Graduates Securing Employment in Animal Processing Over the Last Five Years ...

25 Ranking of Meat Processing Skill Level of Students in Meat Processing Program.

26 Animal Processing Performance Level of Agricultural Educators

27 Agricultural Educator's Source of Knowledge and Skill of Animal Processing .50

28 Agricultural Educators Interest in Teaching Animal Processing ..........................52

29 Teaching Methods Used by Agricultural Educators for Animal Processing ..........54

30 Agricultural Teacher's Interest in Attending Professional Development

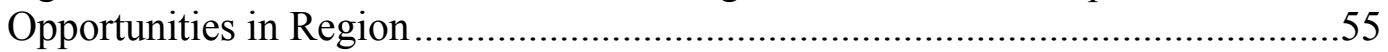

31 Agricultural Teacher's Interest in Attending Professional Development Opportunities at WVU

32 Agricultural Educators' Flexibility in their Curriculum to Include More

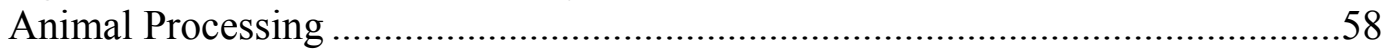

33 Agricultural Educator's Interest in Starting a Meat Processing Program..............58

34 Agricultural Educator's Concerns with Starting a Meat Processing Facility/Program

35 Agricultural Educators Background in Animal Processing.... .60

36 Agricultural Educator's Interest in Attending Workshops Sponsored by WVU.

37 Teaching Methods of Animal Processing without a Meat Facility.........................61

38 Teaching Locations of Animal Processing without a Meat Facility......................61

39 Animals Processed without a Meat Facility........................................................62

40 Agricultural Educator's Interest in Building a Meat Processing Lab ....................62

41 Concerns with Starting a Meat Processing Facility/Program ................................63

42 Agricultural Educators Background in Animal Processing ..................................63

43 Agricultural Educator's Interest in Attending Meat Processing Workshops Sponsored by WVU. 


\section{CHAPTER I}

\section{Introduction}

The American farmer is one of the world's most productive individuals in the

food and fiber system. Each United States farmer produces enough food and fiber to feed himself and 155 others (American Farm Bureau Federation, 2013). While 2.2 million farms are found across the United States, there is another large group of individuals involved in agriculture careers (American Farm Bureau Federation, 2013).

Approximately 22 million individuals currently work in over 200 agricultural related careers in areas such as: agribusiness, forestry, food science, animal science, plant and soil science, horticulture, communications and resource development (National Ag Day, n.d.). In 2012, agricultural products made up 10\% of U.S. exports (Joint Economic Committee, 2013).

As the relevance of the agricultural industry increases, so does the push for locally grown products. According to the United States Department of Agriculture's Census of Agriculture from 2002-2007, there was a $39 \%$ increase in the number of West Virginia farmers selling products directly to consumers (United States Department of Agriculture, 2007). According to the Washington Post, officials have stated that West Virginia's growing local food movement may become a model for 12 other Appalachian states (Washington Post, 2013). West Virginia has become a leader in the local food movement. Since 2005, the number of local farmers' markets has more than tripled, from 30 to 93 (West Virginia HUB, 2013). The state has made great strides in drafting a statewide strategic plan that incorporates local food entitled the "Road Map for a Food Economy" (West Virginia HUB, 2013). 
The West Virginia Department of Agriculture supports the local food movement initiative. Walt Helmick, West Virginia Commissioner of Agriculture, stated, "We want West Virginia land to be used by West Virginians to grow a product that West Virginians will consume" (The State Journal, 2013, para. 3). He went on to explain West Virginia's lack of self-sufficiency due to the state importing more than six billion dollars of food (The State Journal, 2013). The Commissioner is making great progress in promoting the local food movement with a special emphasis on the farm-to-school programs. Currently, Commissioner Helmick's focus is on produce for the schools; however, he wants to extend the initiative to meat and poultry (Stewart, 2014).

The local food movement is not exclusive to West Virginia, but is spreading across the United States. A study conducted in Washington County, Nebraska showed that consumers have a high level of interest in local production of foods and they indicated an inclination to pay a premium price for local products (Schneider \& Francis, 2005). Many public schools are purchasing foods for their cafeteria from farms in their surrounding areas to provide a fresher food source. During the 2011-2012 school year the Massachusetts Farm to School initiative "was unable to meet the demand for local food from schools eager to bring local food to their students" (Schroeder, 2013). With this rise in demand in the local food market, there is also a demand for people to provide these services (Schroeder, 2013).

In a study conducted in the Pioneer Valley of Massachusetts, the local food system was already creating job opportunities. Research showed:

Job growth is evident on farms; business growth and development is evident in food manufacturing; innovation and business development is 
happening in food distribution; and food waste management is poised to change in ways that hold possibility for business expansion and job creation. (Schroeder, 2013, p. 3)

The publication, A Feasibility Template for Small, Multi-Species Meat Processing Plants, explained that a surge in demand for meat processing services had resulted from the local food movement in combination with USDA's Know Your Farmers, including an increased demand for organic/natural meats (Holcomb, Flynn, \& Kenkel , 2012). One job area that has grown as a result of the local food movement was cutting and packing meat to address local demand. Related industries such as processing kitchens, slaughterhouses, and distribution companies could also grow from this movement (Schroeder, 2013). In West Virginia, if everyone who lived in the state consumed locally grown food during the growing season, approximately 1,700 jobs would result (West Virginia HUB, 2013). The mandate for fresh, local meat products creates a demand for people with the training and skills to provide those products (Schroeder, 2013).

Since the agriculture industry has a variety of career and job opportunities, the education system in the United States has developed and operated high school programs that give students the knowledge and skills needed to enter into and be successful in these agricultural careers. These programs have existed since the mid to late $19^{\text {th }}$ century and have been supported by a number of federal legislative efforts including: Smith Hughes Act of 1917, George Barden Act of 1946, Vocational Education Act of 1963, Vocational Education Amendment of 1976, and the Carl D. Perkins Vocational Education Acts of 1984, 1998, and 2006 (Fravel, 1989). Secondary agricultural education focuses on instruction that will provide students with a wide range of opportunities for entry-level 
employment or prepare them to further their education in this diverse field (Illinois Agricultural Education, n.d.).

Agricultural education programs have been a part of the high school curriculum in West Virginia since before the Smith Hughes Act of 1917 (Patterson, n.d.). In 20132014, over 5,000 West Virginia high school students received instruction in agricultural education that involved 76 programs in 46 of the 55 counties (J. Hughes, personal communication, June 20, 2014). In 2014-2015, students in West Virginia will be able to study agricultural subjects in seven pathways and eleven concentrations including: Agribusiness Systems; Animal Processing; Animal Systems; Forest Industry; Mining Extraction; Natural Resources Management; Oil and Gas Extraction and Distribution; Parks and Recreation; Plant Systems; Power, Structural, and Technical Systems; and Turf and Landscape Systems (West Virginia Department of Education, n.d.).

Considerable investments have been made in the area of animal processing. As a result, 32 schools in West Virginia have access to educational facilities that allow them to prepare students in meat fabrication (J. Hughes, personal communication, January 15, 2014). According to the West Virginia Department of Agriculture, "High school meat processing programs are growing in popularity in West Virginia, providing workforceready graduates with the training to help meet demand for locally-grown products" (West Virginia Department of Agriculture, 2012, para. 1). In 2013, 335 students took the animal processing pathway and 13 completed the program and passed the completer's exam.

A meat processing facility is a way for students to gain knowledge and skills that are vital for future employment. Examples of meat facility instruction include: trim, 
slice, and section carcasses for further processing; cut and trim meat to prepare for packing; cut, trim, bone, tie, and grind beef, pork, and poultry to prepare meat in cooking form; process primal parts into cuts that are ready for retail use; wrap, weigh, label and price cuts of meat; and prepare and place meat cuts and products in display counter (West Virginia Department of Education, n.d.). Other skills may include curing hams and bacons, processing wild game carcasses, value-added processing such as summer sausage, breakfast sausage, and jerky, and learning how to safely operate meat processing equipment. It is important for agricultural education teachers to have the skills to prepare their students. Agricultural education teachers need professional development opportunities in new and developing topics in their content area (Moeini, 2008). For a meat facility to be operated at its full potential, it is essential for teachers in the establishments to have knowledge and skill to create a flourishing and safe learning environment.

If West Virginia and the United States are going to prepare students for entry level positions in the meats processing industry, instructors are needed who have the expertise to prepare these individuals. Currently there is little information on the knowledge and skill level of instructors operating high school meats processing facilities. Therefore, a study is needed to determine the expertise of the instructors and the training needs of these individuals in the area of meats processing.

\section{Purpose of Study}

The purpose of this study was to determine the types of meats processing equipment and facilities that exist in West Virginia's high school agricultural education programs. In addition, training needs of the agricultural education instructors will be 
determined. Variables that were investigated included: (a) meat processing facilities in agricultural education programs (b) meat processing equipment (c) number of students that use the meat processing facility (d) teaching methods used to deliver meat processing material (e) teachers performance levels on processing animals (f) views on professional development opportunities hosted by West Virginia University and (g) types of professional development that is needed.

The study provided information regarding the level of interest in attending workshops and adult education classes to help improve the instruction of their students. This information will be valuable to agricultural education teachers, agricultural education students, state staff, and West Virginia University faculty to help educate teachers to prepare students to enter employment.

\section{Objective of the Study}

The objectives of the study are reflected in the following research questions:

1. How many agricultural education programs in West Virginia have a meat processing facility?

2. How much space is available in the meat facilities?

3. What meat processing equipment is used in the program?

4. What species of food animals are students taught to process?

5. How was the program funded?

6. What are the performance levels for those teachers who teach animal processing?

7. What teaching methods are being used to teach meat processing materials?

8. How many days per school year is each program's facility used? 
9. What kind of meat processing, professional development opportunities would agricultural teachers find useful?

\section{Limitations of the Study}

The study was limited to agricultural education programs in West Virginia. All currently employed agricultural teachers were included in this study. 


\section{CHAPTER II}

\section{Review of Literature}

\section{Locally Grown Foods}

In the early 1900s farmers performed their chores by hand. Food for the farmer and his family, and feed for their livestock came off their own land. The average size of a farm was 146 acres; however as more modern technology developed there was a shift in American agriculture (Living History Farm, n.d.). The number of farmers began to shrink, and in 1950 there were 355,000 fewer farms than in 1900 (Living History Farm, n.d.). From 1950 to 1970 the number of farms declined by half and the number of people on farms dropped from over 20 million to less than 10 million (Living History Farm, n.d.). The average size of a farm expanded from 215 acres in 1950 to almost 400 acres by 1969 (Living History Farm, n.d.).

The American Farm Bureau Federation stated that “today's farmers produce 252 percent more food with two percent fewer inputs compared with 1950." (Dickenson, Joseph \& Ward, n.d., para 1 Local Food Movement) The number of farms has continued to decline from six million farms in 1940 to a little over two million farms in 2002 (Living History Farm, n.d.). In 2007, only six million people lived on a farm with the farm size doubling since 1940 (United States Environmental Protection Agency, n.d.). Agriculture has turned into large-scale production of monoculture commodities that has allowed Americans to spend less than $10 \%$ of their disposable income on food (United States Department of Agriculture, 2013).

While there have been many gains through industrialized agriculture, critics charge that this system is unsustainable due to waste production and high dependence on 
foreign oils due to transportation needs (Dickenson, Joseph \& Ward, n.d.). An alternative to this type of agriculture is a smaller scale model that focuses on producing and consuming locally. The popularity of this approach, also known as the local food movement, has increased exponentially. Between 2002 and 2007, direct-to-consumer sales of agriculture increased by $39 \%$ (West Virginia HUB, n.d.). Furthermore, the number of farmers' markets increased by 92\% from 1998-2009 (Martinez, S., et al. 2010).

\section{The National Meat Industry}

According to a study conducted on the food system in the Pioneer Valley, "Meat production is a huge part of the U.S. agriculture sector, representing more than half the value of all agricultural products." (Dickenson, Joseph \& Ward, n.d. National Meat Industry para. 1) Much like other trends in agricultural production, meat processing has endured dramatic consolidation since the 1950s; which has accounted for a drop in the number of USDA inspected slaughterhouses by 20\% from 2002 to 2007 (Dickenson, Joseph \& Ward, n.d.). This consolidated industry produces in high volume and large scale. With fewer meat processing facilities there is less need for meat processors. However, with a move to the small scale model and locally grown foods, the food system will require a large number of small-scale meat processors (Dickenson, Joseph \& Ward, n.d.).

Despite the fact that meat processing has been drastically consolidated, small meat processing continues to be important in rural communities. A recent survey of small meat processors, conducted by the Leopold Center's Small Meat Processors Working Group, showed that there is a need for highly trained labor within the meat process 
industry (Leopold Center for Sustainable Agriculture, 2011). Furthermore, a study conducted in Massachusetts showed that employees within this industry have little or no experience processing meat, and that in this field it falls upon the owner to train the employees. (Dickenson, Joseph \& Ward, n.d.).

As the demand for fresh, local food increases, farmers and agricultural entrepreneurs will need to develop new skills to match these trends (Virginia Department of Education, 2013). The Virginia Department of Education explained that this trend will impact agricultural jobs, such as meat processing. The demand will also create positions to educate people so that they may enter these occupations (Virginia Department of Education, 2013). Furthermore, the study showed that Career and Technical Education in agriculture is vital in preparing students for entry-level jobs (Virginia Department of Education, 2013).

\section{Agricultural Education}

According to the National FFA Organization, the mission of agricultural education is as follows: "Agricultural education prepares students for successful careers, and a lifetime of informed choices in the global agriculture, food, fiber, and natural resource systems." Students who enroll in agricultural education have the opportunity to develop leadership skills, personal growth, and career success. Agricultural education encompasses a three-circle model of instruction. The three circles include classroom/laboratory instruction, Supervised Agricultural Experience (SAE) programs, and the National FFA Organization (The National FFA Organization, n.d.).

In the classroom, agricultural education teachers focus their teaching on

agriculture, food and natural resources (The National Association of Agricultural 
Educators, n.d.). These subjects allow students to learn a wide range of skills while enhancing their science, math, communication, leadership, management, and technology skills (The National Association of Agricultural Educators, n.d.). According to the West Virginia Department of Agriculture, one area that is growing in West Virginia is the meats processing programs in secondary education (West Virginia Department of Agriculture, 2012). The West Virginia Department of Agriculture stated that "The mainstay of meat programs continue to be the FFA Ham and Bacon Program in which most of the work is done outside of regular class hours" (West Virginia Department of Agriculture, 2012, para. 4).

West Virginia FFA's Ham, Bacon, and Egg Program, which is unique to the state, allows students that are enrolled in agricultural education classes to participate in their local, regional and/or state show and sale (West Virginia Department of Agriculture, 2013). Students have the opportunity to process, cure, and trim the hams and bacons from a hog. Hams and bacons are then judged, with the best hams and bacons being eligible for the state competition. The state sale started in 1941 and has generated over one million dollars for students (West Virginia Department of Agriculture, 2013). Students have the prospect to make a profit while learning skills that will be helpful in securing employment in the animal processing field.

Not all agricultural education programs focus on a ham and bacon production, or even have a meat processing facility; however a push exists for more meat processing skills to provide students with hands on training (West Virginia Department of Agriculture, 2012). Even though not all programs are equipped with meat processing facilities, the Content Skill Sets (CSS's) for West Virginia require that basic meat 
processing skills be taught in every program. The first course required for students to take, in the seven pathways, is Introduction to Agriculture, Food, and Natural Resources (West Virginia Department of Education, n.d.). The skill set for this beginner course requires students to learn the history of the meat industry, and to practice making pork sausage (West Virginia Department of Education, n.d.). This class offers one unit on meat processing; while the animal processing pathway allows students to take classes such as the Fundamentals of Animal Processing in which they receive more in depth knowledge (West Virginia Department of Education, n.d.).

\section{Professional Development}

While meat processing programs are very beneficial to the students enrolled in the classes, there are obstacles that must be overcome. For instance, teachers are now faced with higher expectations due to new technology advancements, a diverse population, and a continuous change in expectations of quality education (Moeini, 2008). Furthermore, agricultural education has changed tremendously over the last thirty years. Agricultural educators are continually challenged to better prepare their students to enter the work force, while following the mission of agricultural education. (Duncan, Ricketts, Peake, \& Uessler, 2005).

When meat processing in agricultural education programs started to grow, teachers had the opportunity to receive endorsements for teaching meat fabrication in the 1980s. (S. Gartin, personal communication, February 15, 2014). This opportunity is no longer available to teachers in West Virginia, and as agricultural education expanded the expectation of knowing a wide variety of agricultural content developed without incentives like those in the 1980s. Before entering the teaching field, an educator can 
receive training from a variety of sources such as their high school agricultural education program, their home farm, and college courses. For meat processing training, one college course with attendant lab is offered at West Virginia University; this course is FDST 365, Muscle Food Technology. This course places an emphasis on slaughtering, fabrication, handling, manufacturing, muscle structure and composition, and conversion of muscle to meat, and it covers food animal species such as cattle, sheep, hogs, poultry, and fish (West Virginia University, 2014). However, this course is not required to become certified in agricultural education; it is an elective class.

A solution to some of the obstacles that teachers face would be to have in-service education (Ewing, Gill, Radhakrishna \& Clark, n.d.). In a study that was conducted in Pennsylvania on identifying in-service needs of secondary agricultural teachers, meat science and evaluation were found to be one of the desired topics for teachers (Ewing, Gill, Radhakrishna \& Clark, n.d.). By providing in-service training in meat science, proper training and support will be provided to teachers to better educate their students.

\section{Summary}

The local food movement is agriculture that is smaller-scale and plants and animals are produced and consumed locally (Dickenson, Joseph \& Ward, n.d.). Every year it continues to increase and become more relevant. The meat industry in America is centralized, with few commercial-scale facilities; however, the push for local food creates a need for many small meat processing facilities and processors (Dickenson, Joseph \& Ward, n.d.). Even though meat processing is mostly done at large-scale operations, small processing facilities are still important to small communities (Leopold Center for Sustainable Agriculture, 2011). 
With the local food movement's continued growth, students will need to be educated to obtain these entry-level positions. Career and Technical Education in agriculture to prepare students is the answer (Virginia Department of Education, 2013). Agricultural education helps students prepare for successful careers. However, there are many challenges that teachers face including: higher expectations, newer technology, diverse populations, and requirement for expertise in a diverse and wide array of agricultural topics (Moeini, 2008). Professional development and in-service trainings can provide teachers with the knowledge and skills they need to operate a successful meats processing program. 


\section{CHAPTER III}

\section{Methodology}

\section{Purpose of Study}

The purpose of this study was to determine the types of meats processing equipment and facilities that exist in West Virginia's high school agricultural education programs. In addition, training needs of the agricultural education instructors will be determined. Variables that were investigated included: (a) meat processing facilities in agricultural education programs (b) meat processing equipment (c) number of students that use the meat processing facility (d) teaching methods used to deliver meat processing material (e) teachers performance levels on processing animals (f) views on professional development opportunities hosted by West Virginia University and (g) types of professional development that is needed.

The study provided information regarding the level of interest in attending workshops and adult education classes to help improve the instruction of their students. This information will be valuable to agricultural education teachers, agricultural education students, state staff, and West Virginia University faculty to help educate teachers to prepare students to enter employment.

\section{Objective of the Study}

The objectives of the study are reflected in the following research questions:

1. How many agricultural education programs in West Virginia have a meat processing facility?

2. How much space is available in the meat facilities?

3. What meat processing equipment is used in the program? 
4. What species of food animals are students taught to process?

5. How was the program funded?

6. What are the performance levels for those teachers who teach animal processing?

7. What teaching methods are being used to teach meat processing materials?

8. How many days per school year is each program's facility used?

9. What kind of meat processing, professional development opportunities would agricultural teachers find useful?

\section{Research Design}

For this study, a descriptive research design was selected to obtain information. Descriptive research "uses instruments such as questionnaires and interviews to gather information from groups of individuals" (Ary, Jacobs \& Sorensen, 2009, p. 28). This design was used to gather information about the characteristics of meat processing facilities in agricultural education programs in West Virginia. According to Ary, Jacobs \& Sorensen (2009), "Surveys permit the researcher to summarize the characteristics of different groups or to measure their attitudes and opinions toward some issue" (p. 30). A survey requires careful planning, implementation, and analysis in order to yield reliable and valid information. An electronic survey was selected for this study to allow respondents to work at their own pace. The advantages of the electronic survey are: to have prompter returns, lower item nonresponse, and more complete answers to openended questions (Dillman, 2000). 


\section{Population}

The target population was all agricultural education teachers in West Virginia. The accessible population was all current agricultural education teachers in West Virginia that were employed during the spring of 2014 and could be reached by email.

Five sources of survey errors that can affect the accuracy of the information collected include frame error, sampling error, nonresponse error, selection error and measurement error (Ary, Jacobs, \& Sorenesen, 2009). Frame error was avoided by using a list of the entire population. Sampling error was avoided by conducting a census of the accessible population. Non-response error was examined by comparing early and late responders. No differences were found between the two groups. Selection error was avoided by using an official list of agricultural educators in West Virginia. Measurement error was avoided by using a valid and reliable instrument.

\section{Instrumentation}

Survey participants completed a web-based questionnaire developed by the researcher and hosted on www.surveymonkey.com. The research instrument was developed by reviewing research related to the topic. Using this information, questions were developed for the instrument. The questionnaire was designed following established social science practices. The instrument was broken down into three different segments. The first segment was for respondents who teach animal processing and had access to a meat processing facility, the second segment was for those who do not teach animal processing, and the third segment was for those who teach animal processing but do not have access to a meat processing facility. 
The first segment, for those who responded "yes" to teaching animal processing and having a meat processing facility, was the most in depth with questions on areas that included: meat processing facilities/ program, meat processing equipment, agricultural education students, teaching methods, teacher's animal processing background, teacher's interest in animal processing, professional development needs and demographics. The questions used five types of questions: yes/no, multiple choice, multiple response, open ended, and Likert scale.

The second segment, for those who responded "no" to teaching animal processing, consisted of questions on areas that included: interest in starting a meat processing program, concerns with starting a program, background in animal processing, and interest in attending meat processing workshops. The questions were composed of three types of questions: yes/no, multiple response, and Likert scale.

The third segment, for those who responded 'yes' to teaching animal processing and "no" to having access to a meat processing facility", consisted of questions that address: teaching methods, location of teaching, animals processed, interest in building a meat processing lab, concerns with starting a program, background in animal processing, and interest in attending meat processing workshops. The questions were composed of three types of questions: yes/no, multiple response, and Likert scale.

\section{Reliability/Validity}

The instrument was presented to a panel of experts to establish its content and face validity. The panel consisted of teacher educators in Agricultural and Extension Education and Animal and Nutritional Sciences at West Virginia University. Each one of these individuals has had extensive teaching and/or Extension field experience, with one 
having an extensive background in meat science. The panel of experts concluded that the instrument had content and face validity.

Reliability is the ability of the scores produced by an instrument to be consistent, repeatable, dependable, and generalized (Ary, Jacobs \& Sorensen, 2009). Reliability was established using the Statistical Package for the Social Sciences' (SPSS) split-half analysis procedures. The unequal length Spearman-Brown value was found to be 69 making the reliability of the instrument exemplary (Robinson, Shaver, \& Wrightsman, 1991).

\section{Data Collection Procedure}

Dillman's Tailored Design Method was used to collect data for this study. The researcher developed the questionnaire through www.surveymonkey.com. An initial email was sent explaining the purpose of the study and contained a cover letter and link to the online survey. Respondents were given seven days to respond. At the end of seven days, a second mailing was sent and respondents were given another seven days to respond. A third and final deadline was sent via email giving respondents another seven days to respond. Personalized emails were sent to agricultural education teachers who were known to have a meat processing facility reminding them of the final deadline. A follow up email was sent the morning of the deadline, reminding participants this was the final deadline for the survey.

\section{Analysis of Data}

Returned questionnaires were retrieved from the online system and entered into an Excel spreadsheet. Data were transferred to Statistical Package for the Social Sciences (SPSS), descriptive analyses were performed on the data. Results were represented as 
frequencies and percentages in both table and narrative form. A total of 103 agricultural teachers were reached via e-mail for the study. Fifty-eight individuals responded for a $56.31 \%$ response rate.

According to Dillman et al. (2009), "nonresponse error occurs when people selected for the survey who do not respond are different from those who respond in a way that is important to the study" (p. 17). Non-response error was addressed by comparing early respondents to late respondents. A chi-square test of independence was performed to determine if there was a significant relationship between early and late respondents. The three variables that were chosen included: if the respondent teaches animal processing $(\mathrm{chi}=0.30, \mathrm{df}=1)$, number of days the meat processing facility is used $(\mathrm{chi}=$ $3.38, \mathrm{df}=3)$, and years of teaching experience $(\mathrm{chi}=5.63, \mathrm{df}=5)$. These variables were selected because they were describing traits of the population. The chi-square values were not significant $(\alpha \leq .05)$. It was concluded that non-respondents were similar to respondents (Ary, Jacobs, \& Sorensen, 2009), therefore generalization could be made to the entire population.

\section{Use of Findings}

Findings can be used by agricultural educators, state supervisors, students and faculty at West Virginia University. The study provided information needed to consider feasibility of professional development opportunities for agricultural educators in West Virginia. Through this study one can determine teachers' attitudes toward professional development in meat processing sponsored by West Virginia University while obtaining valuable information on the meat processing facilities that are being used. 


\section{CHAPTER IV}

\section{Findings}

\section{Purpose of Study}

The purpose of this study was to determine the types of meats processing equipment and facilities that exist in West Virginia's high school agricultural education programs. In addition, training needs of the agricultural education instructors will be determined. Variables that were investigated included: (a) meat processing facilities in agricultural education programs (b) meat processing equipment (c) number of students that use the meat processing facility (d) teaching methods used to deliver meat processing material (e) teachers performance levels on processing animals (f) views on professional development opportunities hosted by West Virginia University and (g) types of professional development that is needed.

The study provided information regarding the level of interest in attending workshops and adult education classes to help improve the instruction of their students. This information will be valuable to agricultural education teachers, agricultural education students, state staff, and West Virginia University faculty to help educate teachers to prepare students to enter employment.

\section{Objective of the Study}

The objectives of the study are reflected in the following research questions:

1. How many agricultural education programs in West Virginia have a meat processing facility?

2. How much space is available in the meat facilities?

3. What meat processing equipment is used in the program? 
4. What species of food animals are students taught to process?

5. How was the program funded?

6. What are the performance levels for those teachers who teach animal processing?

7. What teaching methods are being used to teach meat processing materials?

8. How many days per school year is each program's facility used?

9. What kind of meat processing, professional development opportunities would agricultural teachers find useful?

The study was limited to the 103 agricultural education teachers employed in West Virginia during the 2013-2014 school year. Fifty-eight teachers (56.31\%) responded to the survey.

\section{Agricultural Educators who Teach Animal Processing}

The respondents were asked if they taught animal processing as a part of their high school agricultural education instruction program. Forty-five respondents $(77.59 \%)$ did not teach animal processing and thirteen respondents $(22.41 \%)$ did teach animal processing (see Table 1).

Table 1

Agricultural Educators Who Teach Animal Processing $(N=58)$

\begin{tabular}{lcc}
\hline & $\mathrm{N}$ & $\%$ \\
\hline No & 45 & 77.59 \\
Yes & 13 & 22.41 \\
\hline
\end{tabular}

The 13 respondents who indicated they taught animal processing were directed to a series of questions about their program and facilities. The first question inquired about access to a meat processing facility. Of the respondents who taught animal processing, 
two $(15.38 \%)$ did not have access to a meat processing facility. Eleven respondents $(84.62 \%)$ had access to a meat processing facility (see Table 2 ). Of those instructors, 11 respondents $(10.00 \%)$ reported that the meat facility was located at their school.

Table 2

Agricultural Educators Who Teach Animal Processing and Had Access to a Meat Facility $(N=13)$

\begin{tabular}{lcc}
\hline & $\mathrm{N}$ & $\%$ \\
\hline No & 2 & 15.38 \\
Yes & 11 & 84.62 \\
\hline
\end{tabular}

\section{Demographics of Respondents}

The respondents were asked to indicate their gender. Eight respondents (88.89\%) who taught animal processing and had a meat processing facility indicated that they were male. One respondent (11.11\%) was female (see Table 3).

Table 3

Gender of Agricultural Educators $(N=9)$

\begin{tabular}{lcc}
\hline & $\mathrm{N}$ & $\%$ \\
\hline Male & 8 & 88.89 \\
Female & 1 & 11.11 \\
\hline
\end{tabular}

Using ten-year increments, participants who taught animal processing and had a meat processing facility were asked to indicate their age. Two $(22.22 \%)$ participants indicated they were $21-30$ years of age. One respondent $(11.11 \%)$ identified they were in the $31-40$ year old age category. Two respondents $(22.22 \%)$ indicated they were $41-50$ 
years old, while four (44.45\%) respondents identified they were 51-60 years old (see Table 4).

Table 4

Age of Agricultural Educators $(N=9)$

\begin{tabular}{lcc}
\hline & $\mathrm{N}$ & $\%$ \\
\hline $21-30$ years & 2 & 22.22 \\
$31-40$ years & 1 & 11.11 \\
$41-50$ years & 2 & 22.22 \\
$51-60$ years & 4 & 44.45 \\
60 years and over & 0 & 0.00 \\
\hline
\end{tabular}

Using five-year increments, participants who taught animal processing and had a meat processing facility were asked to indicate their years of teaching experience. One respondent (11.11\%) identified themselves as having 1-5 years of teaching experience, one respondent (11.11\%) had 6 -10 years, one respondent (11.11\%) had 11-15 years, and one respondent $(11.11 \%)$ indicated they had 16-20 years of teaching experience. The final category, more than 25 years of teaching, had four respondents (44.45\%) (see Table 5). 
Table 5

Years of Teaching Experience $(N=9)$

\begin{tabular}{lcc}
\hline & $\mathrm{N}$ & $\%$ \\
\hline $1-5$ years & 1 & 11.11 \\
$6-10$ years & 1 & 11.11 \\
$11-15$ years & 1 & 11.11 \\
$16-20$ years & 1 & 11.11 \\
$21-25$ years & 1 & 11.11 \\
More than 25 years & 4 & 44.45 \\
\hline
\end{tabular}

Respondents who taught animal processing and had a meat processing facility were asked to indicate their highest level of education. One respondent (11.11\%) reported that their highest level of education was a Bachelor's degree. One respondent $(11.11 \%)$ indicated that a Bachelor's +15 was their highest level of education. Four respondents (44.45\%) reported they had a Master's +15 , one $(11.11 \%)$ identified themselves as having a Master's +30 , and two (22.22\%) had a Master's +45 (see Table 6).

Table 6

Highest Level of Education of Agricultural Education Teachers $(N=9)$

\begin{tabular}{llc}
\hline & $\mathrm{N}$ & $\%$ \\
\hline Bachelor's & 1 & 11.11 \\
Bachelor's +15 & 1 & 11.11 \\
Master's & 0 & 0.00 \\
Master's +15 & 4 & 44.45 \\
Master's +30 & 1 & 11.11 \\
Master's +45 & 2 & 22.22 \\
Doctorate & 0 & 0.00 \\
\hline
\end{tabular}


Respondents who taught animal processing and had a meat processing facility were asked to indicate the type of school district in which they teach. Of the respondents seven $(77.78 \%)$ indicated they taught in a rural-farm district. One individual $(11.11 \%)$ taught in a rural-nonfarm area, and one (11.11\%) taught in a suburban school district (see Table 7).

Table 7

Type of School District Served by the Agricultural Education Teacher $(N=9)$

\begin{tabular}{lcc}
\hline & $\mathrm{N}$ & $\%$ \\
\hline Rural Farm & 7 & 77.78 \\
Rural Nonfarm & 1 & 11.11 \\
Suburban & 1 & 11.11 \\
Urban & 0 & 0.00 \\
\hline
\end{tabular}

\section{Meat Processing Facilities}

Teachers who responded that they taught animal processing and had access to a meat processing facility were asked questions on their meat processing program. Four respondents $(36.36 \%)$ indicated they were single teacher agricultural education programs, four respondents $(36.36 \%)$ reported having two teachers, one respondent $(9.09 \%)$ indicated that their program had three teachers, and two participants (18.19\%) reported that there were four teachers in their agricultural education program.

Respondents were also asked to indicate how many teachers from their program use the meat processing facility. Nine respondents $(81.82 \%)$ reported that only one teacher from the program used the meat processing facility. One respondent $(9.09 \%)$ 
indicated that two teachers used the facility and one respondent (9.09\%) also indicated that three teachers used the meat facility (see Table 8).

Table 8

Number of Teachers in Agricultural Education Program and who Use Meat Facility ( $N=$ 11)

\begin{tabular}{ccccc}
\hline & \multicolumn{2}{c}{ Teachers in Ag. Education Program } & \multicolumn{2}{c}{ Teachers who Use Meats Facility } \\
\cline { 2 - 5 } & $\mathrm{N}$ & $\%$ & $\mathrm{~N}$ & $\%$ \\
\hline 1 & 4 & 36.36 & 9 & 81.82 \\
2 & 4 & 36.36 & 1 & 9.09 \\
3 & 1 & 9.09 & 1 & 9.09 \\
4 & 2 & 18.19 & 0 & 0.00 \\
\hline
\end{tabular}

Respondents who taught animal processing and had a meat processing facility were asked to provide information on the equipment in their meat processing facility. They were to indicate how many pieces of equipment were purchased new, purchased used, and/or donated to the meat facility. Respondents had an average of 1.54 meat grinders $(\mathrm{SD}=2.30)$ in their facility with a mean of 10.00 unit $(\mathrm{SD}=2.45)$ purchased used and .54 units $(\mathrm{SD}=.52)$ purchased new. The number of grinders ranged from 0 to 9 with a total of 20 units in the 11 programs. Respondents had an average of 10.00 mixers $(\mathrm{SD}=2.45)$ in their facility with a mean of .15 units $(\mathrm{SD}=.38)$ purchased new and .85 units $(\mathrm{SD}=2.48)$ purchased used. The number of grinders ranged from 0 to 9 with a total of 13 units in the 11 programs. Respondents had an average of 1.77 meat slicers (SD $=2.31)$ in their facility with a mean of .54 units $(\mathrm{SD}=.52)$ purchased new, .92 units $(\mathrm{SD}$ $=2.47)$ purchased used, .15 units $(\mathrm{SD}=.55)$ donated, and .15 units $(\mathrm{SD}=.38)$ acquired 
by other means. The number of slicers ranged from 0 to 9 with a total of 23 units in the 11 meat processing programs. Respondents had an average of 1.62 hand saws $(\mathrm{SD}=$ $1.12)$ with a mean of 1.38 units $(\mathrm{SD}=1.26)$ purchased new and $.23(\mathrm{SD}=.60)$ purchased used. The number of hand saws ranged from 0 to 4 with a total of 21 units in 11 programs.

Respondents had an average of 1.69 vacuum packers $(\mathrm{SD}=2.32)$ with a mean of 1.46 units $(\mathrm{SD}=2.33)$ purchased new and .23 units $(\mathrm{SD}=.44)$ purchased used. The number of vacuum packers ranged from 0 to 9 with a total of 22 units in the 11 programs. Respondents had an average of 1.15 breaking saws $(\mathrm{SD}=2.44)$ with a mean of .85 units $(\mathrm{SD}=2.48)$ purchased new, .23 units $(\mathrm{SD}=.60)$, and .08 units $(\mathrm{SD}=.28)$ donated.

The number of breaking saws ranged from 0 to 9 with a total of 22 units in the 11 programs. Respondents had an average of .77 smokers $(\mathrm{SD}=.44)$ with a mean of .62 units $(\mathrm{SD}=.51)$ purchased new, .62 units $(\mathrm{SD}=.51)$ purchased used, and .08 units $(\mathrm{SD}=$ .28) were acquired by other means. The number of smokers ranged from 0 to 1 with a total of 10 smokers in the 11 programs. Respondents had an average of 1.31 meat tenderizers $(\mathrm{SD}=2.36)$ with a mean of 1.23 units $(\mathrm{SD}=2.39)$ purchased new and .08 units $(\mathrm{SD}=.28)$ purchased used. The number of meat tenderizers ranged from 0 to 9 with a total of 17 units in the 11 programs. Respondents had an average of .92 patty makers $(\mathrm{SD}=2.47)$ with a mean of .85 units $(\mathrm{SD}=2.48)$ purchased new and .08 units $(\mathrm{SD}=.28)$ donated. The number of patty makers ranged from 0 to 9 with a total of 12 units in the 11 programs. Respondents had an average of 1.23 stuffers (vacuum or piston) $(\mathrm{SD}=2.39)$ with a mean of 1.23 units $(\mathrm{SD}=2.39)$ purchased new. The number of stuffers ranged from 0 to 9 with a total of 16 units in the 11 programs. 
Respondents had an average of 80.00 boning knives $(\mathrm{SD}=4.71)$ with a mean of 80.00 units $(\mathrm{SD}=4.71)$ purchased new. The number of boning knives ranged from 0 to 11 with a total of 104 units in the programs. Respondents had an average of 1.69 breaking knives $(\mathrm{SD}=2.56)$ with a mean of 1.69 units $(\mathrm{SD}=2.56)$ purchased new. The number of breaking knives ranged from 0 to 9 with a total of 22 units in the 11 programs.

Respondents had an average of 1.54 band saws $(\mathrm{SD}=2.30)$ with a mean of .54 units (SD $=.52)$ purchased new and 10.00 units $(\mathrm{SD}=2.45)$ purchased used. The number of band saws ranged from 0 to 9 with a total of 20 band saws in the 11 programs (see Table 9).

Table 9

Meat Processing Equipment that was Purchased New, Purchased Used, or Donated

\begin{tabular}{crrrrr}
\hline & M & SD & Min & Max & Sum \\
\hline Grinder & & & & & \\
New & .54 & .52 & 0 & 1 & 7 \\
Used & 10.00 & 2.45 & 0 & 9 & 13 \\
Donated & 0.00 & 0.00 & 0 & 0 & 0 \\
Other & 0.00 & 0.00 & 0 & 0 & 0 \\
Total & 1.54 & 2.30 & 0 & 9 & 20 \\
Mixer & & & & & \\
New & .15 & .38 & 0 & 1 & 2 \\
Used & .85 & 2.48 & 0 & 9 & 11 \\
Donated & 0.00 & 0.00 & 0 & 0 & 0 \\
Other & 0.00 & 0.00 & 0 & 0 & 0 \\
Total & 10.00 & 2.45 & 0 & 9 & 13 \\
\hline
\end{tabular}


Table 9 (continued)

Meat Processing Equipment that was Purchased New, Purchased Used, or Donated

\begin{tabular}{lccccc}
\hline \multicolumn{1}{l}{ Slicer } & M & SD & Min & Max & Sum \\
New & .54 & .52 & 0 & 1 & 7 \\
Used & .92 & 2.47 & 0 & 9 & 12 \\
Donated & .15 & .55 & 0 & 2 & 2 \\
Other & .15 & .38 & 0 & 1 & 2 \\
Total & 1.77 & 2.31 & 0 & 9 & 23
\end{tabular}

\section{$\underline{\text { Hand Saw }}$}

\begin{tabular}{lrrrrr} 
New & 1.38 & 1.26 & 0 & 4 & 18 \\
Used & .23 & .60 & 0 & 2 & 3 \\
Donated & 0.00 & 0.00 & 0 & 0 & 0 \\
Other & 0.00 & 0.00 & 0 & 0 & 0 \\
Total & 1.62 & 1.12 & 0 & 4 & 21 \\
Vacuum Packer & 1.46 & 2.33 & 0 & 9 & 19 \\
\hline New & .23 & .44 & 0 & 1 & 3 \\
Used & 0.00 & 0.00 & 0 & 0 & 0 \\
Donated & 0.00 & 0.00 & 0 & 0 & 0 \\
Other & 1.69 & 2.32 & 0 & 9 & 22 \\
\hline Total & & & & & \\
\hline
\end{tabular}


Table 9 (continued)

Meat Processing Equipment that was Purchased New, Purchased Used, or Donated

\begin{tabular}{|c|c|c|c|c|c|}
\hline & M & SD & Min & Max & Sum \\
\hline \multicolumn{6}{|l|}{ Breaking Saw } \\
\hline New & .85 & 2.48 & 0 & 9 & 11 \\
\hline Used & .23 & .60 & 0 & 2 & 3 \\
\hline Donated & .08 & .28 & 0 & 1 & 1 \\
\hline Other & 0.00 & 0.00 & 0 & 0 & 0 \\
\hline \multicolumn{6}{|l|}{ Total } \\
\hline Smoker & .77 & .44 & 0 & 1 & 10 \\
\hline New & .62 & .51 & 0 & 1 & 8 \\
\hline Used & .08 & .28 & 0 & 1 & 1 \\
\hline Donated & 0.00 & 0.00 & 0 & 0 & 0 \\
\hline Other & .08 & .28 & 0 & 1 & 1 \\
\hline Total & 1.15 & 2.44 & 0 & 9 & 15 \\
\hline \multicolumn{6}{|l|}{ Meat Tenderizer } \\
\hline New & 1.23 & 2.39 & 0 & 9 & 16 \\
\hline Used & .08 & .28 & 0 & 1 & 1 \\
\hline Donated & 0.00 & 0.00 & 0 & 0 & 0 \\
\hline Other & 0.00 & 0.00 & 0 & 0 & 0 \\
\hline Total & 1.31 & 2.36 & 0 & 9 & 17 \\
\hline
\end{tabular}


Table 9 (continued)

Meat Processing Equipment that was Purchased New, Purchased Used, or Donated

\begin{tabular}{cccccc}
\hline & M & SD & Min & Max & Sum \\
\hline $\begin{array}{ccc}\text { Patty Maker } \\
\text { New }\end{array}$ & .85 & 2.48 & 0 & 9 & 11 \\
Used & 0.00 & 0.00 & 0 & 0 & 0 \\
Donated & .08 & .28 & 0 & 1 & 1 \\
Other & 0.00 & 0.00 & 0 & 0 & 0 \\
Total & .92 & 2.47 & 0 & 9 & 12
\end{tabular}

\section{$\underline{\text { Stuffer }}$}

\begin{tabular}{cccccc} 
New & 1.23 & 2.39 & 0 & 9 & 16 \\
Used & 0.00 & 0.00 & 0 & 0 & 0 \\
Donated & 0.00 & 0.00 & 0 & 0 & 0 \\
Other & 0.00 & 0.00 & 0 & 0 & 0 \\
Total & 1.23 & 2.39 & 0 & 9 & 16 \\
Boning Knife & 80.00 & 4.71 & 0 & 11 & 104 \\
New & 0.00 & 0.00 & 0 & 0 & 0 \\
Used & 0.00 & 0.00 & 0 & 0 & 0 \\
Donated & 0.00 & 0.00 & 0 & 0 & 0 \\
Other & 80.00 & 4.71 & 0 & 11 & 104 \\
\hline Total & & & & & \\
\hline
\end{tabular}


Table 9 (continued)

Meat Processing Equipment that was Purchased New, Purchased Used, or Donated

\begin{tabular}{cccccc}
\hline & M & SD & Min & Max & Sum \\
\hline Breaking Knife & 1.69 & 2.56 & 0 & 9 & 22 \\
New & 0.00 & 0.00 & 0 & 0 & 0 \\
Used & 0.00 & 0.00 & 0 & 0 & 0 \\
Donated & 0.00 & 0.00 & 0 & 0 & 0 \\
Other & 1.69 & 2.56 & 0 & 9 & 22 \\
Total & .54 & .52 & 0 & 1 & 7 \\
Band Saw & 10.00 & 2.45 & 0 & 9 & 13 \\
New & 0.00 & 0.00 & 0 & 0 & 0 \\
Used & 0.00 & 0.00 & 0 & 0 & 0 \\
Donated & 1.54 & 2.30 & 0 & 9 & 20 \\
Other & & & & & \\
Total & & & 0 & & 0 \\
\hline
\end{tabular}

Respondents who taught animal processing and had a meat processing facility were asked about the square footage of floor space in their meat processing facility, their coolers, and freezers. The mean floor space of the facility was $2,330.50 \mathrm{ft}^{2}$ $(\mathrm{SD}=3231.84)$. The maximum floor space of a facility was $10,000 \mathrm{ft}^{2}$ and the minimum was $40 \mathrm{ft}^{2}$. The average size of a cooler was $291.56 \mathrm{ft}^{2}(\mathrm{SD}=168.39)$, with a maximum of $500 \mathrm{ft}^{2}$ and a minimum of $20 \mathrm{ft}^{2}$. The mean size of a walk-in freezer was $83.50 \mathrm{ft}^{2}$ $(\mathrm{SD}=60.01)$, with a maximum of $180 \mathrm{ft}^{2}$ and a minimum of $25 \mathrm{ft}^{2}$ (see Table 10$)$. 
Table 10

Square Footage of the Floor Space of the Facility, Cooler, and Freezer

\begin{tabular}{lcccc}
\hline & M & SD & Min & Max \\
\hline Facility & 2330.50 & 3231.84 & 40 & 10000 \\
Cooler & 291.56 & 168.39 & 20 & 500 \\
Freezer & 83.50 & 60.01 & 25 & 180 \\
\hline
\end{tabular}

Respondents who taught animal processing and had a meat processing facility were also asked how many chest or upright freezers they had to use for meat processing. There was an average of 2.14 chest or upright freezers $(\mathrm{SD}=1.46)$ in the programs. The minimum number of chest or upright freezers was one and the maximum was four (see Table 11).

Table 11

Number of Chest or Upright Freezers used for Meat Processing

\begin{tabular}{lcccc}
\hline & M & SD & Min & Max \\
\hline Chest or Upright Freezers & 2.14 & 1.46 & 1 & 4 \\
\hline
\end{tabular}

Respondents who taught animal processing and had a meat processing facility were asked how their meat processing facility was funded. There were four different categories. Four schools received funding from a Program Modernization Grant with a mean of $\$ 41,25.00(\mathrm{SD}=\$ 11,814.54)$. The minimum was $\$ 25,000$ and the maximum was $\$ 50,000$. Two programs received money from local fundraising with a mean of $\$ 26,500.00(\mathrm{SD}=\$ 33,234.2)$, a minimum of $\$ 3,000$ and a maximum of $\$ 50,000$. The local Board of Education supplied funding for four programs with a mean of $\$ 153,750.00$ 
$(\mathrm{SD}=\$ 41,855.27)$ per program. The maximum was $\$ 300,000$ and the minimum was $\$ 20,000$. One respondent received donations of $\$ 50,000$ to fund their meat processing facility (see Table 12).

Table 12

Funding for Meat Processing Facility

\begin{tabular}{|c|c|c|c|c|c|}
\hline & M & SD & Schools & Min & Max \\
\hline $\begin{array}{l}\text { Modernization } \\
\text { Grant }\end{array}$ & $\$ 41,25.00$ & $\$ 11,814.54$ & 4 & $\$ 25,000$ & $\$ 50,000$ \\
\hline $\begin{array}{l}\text { Local } \\
\text { Fundraising }\end{array}$ & $\$ 26,500.00$ & $\$ 33,234.02$ & 2 & $\$ 3,000$ & $\$ 50,000$ \\
\hline Local BOE & $\$ 153,750.00$ & $\$ 141,855.27$ & 4 & $\$ 20,000$ & $\$ 300,000$ \\
\hline Donations & $\$ 50,000.00$ & . & 1 & $\$ 50,000$ & $\$ 50,000$ \\
\hline
\end{tabular}

Respondents who taught animal processing and had a meat processing facility were asked how the day-to-day operation of their facility was funded. Seven respondents $(63.64 \%)$ indicated that processing fees for food animals helped fund the day-to-day operation. Three respondents $(27.27 \%)$ reported that processing fees for wild game helped fund the day-to-day operation of the facility. Seven respondents (63.64\%) reported selling meat products that were processed in the meat lab funded the daily operation. Four respondents (36.36\%) indicated the county Board of Education helped fund the day-to-day operation and four respondents also indicated that the FFA Chapter helped fund the daily operation. One respondent (9.09\%) indicated that the FFA Alumni Chapter helped fund the operation of the meat processing facility (see Table 13). 
Table 13

Funding for the Day-to-Day Operation of the Meat Processing Facility $(N=11)$

\begin{tabular}{lcc}
\hline & N & $\%$ \\
\hline Processing Fees for Food Animals & 7 & 63.64 \\
Processing Fees for Wild Game & 3 & 27.27 \\
Selling Meat Products Processed in Lab & 7 & 63.64 \\
County Board of Education & 4 & 36.36 \\
FFA Chapter & 4 & 36.36 \\
FFA Alumni Chapter & 1 & 9.09 \\
\hline
\end{tabular}

Respondents who taught animal processing and had a meat processing facility were asked how many of each animal type they processed during an average school year (August to August). There was a mean of 22.44 beef animals $(\mathrm{SD}=30.32)$ processed with a minimum of one and a maximum of 100 . There was a mean of 70.22 pork $(S D=61.45)$ processed with the minimum of 10 and maximum of 200. There was a mean of 40.00 sheep $(\mathrm{SD}=4.08)$ processed with a minimum of one and a maximum of 10 . Only one respondent reported processing goats and the response indicated that 10 goats were processed. Four chickens were processed at one meat processing facility and one turkey was processed at one facility. The mean for the number of deer processed was 61.25 head $(\mathrm{SD}=45.16)$. The minimum number of deer processed was 15 and the maximum number reported was 100. No one reported that they processed fish (see Table 14). 
Table 14

Number of Animals Processed on Average during a School Year

\begin{tabular}{lcccc}
\hline & M & SD & Min & Max \\
\hline Beef & 22.44 & 30.32 & 1 & 100 \\
Pork & 70.22 & 61.45 & 10 & 200 \\
Sheep & 40.00 & 4.08 & 1 & 10 \\
Goats & 10.00 & 0.00 & 10 & 10 \\
Chickens & 40.00 & 0.00 & 4 & 4 \\
Turkey & 10.00 & 0.00 & 1 & 1 \\
Deer & 61.25 & 45.16 & 15 & 100 \\
Fish & 0.00 & 0.00 & 0 & 0 \\
\hline
\end{tabular}

Respondents who taught animal processing and had a meat processing facility were asked how many days out of the 180 day school year they used their meat processing facility. No one responded that they used their facility 0-29 days or 30-59 days. One respondent (11.11\%) reported that they used their facility $60-89$ days. Four respondents (44.45\%) indicated that they used their facility 90-119 days. Two respondents $(22.22 \%)$ reported $120-139$ days and two respondents $(22.22 \%)$ reported 140-180 days (see Table 15) 
Table 15

Number of Days Agricultural Educators Use Meat Processing Facilities ( $N=9)$

\begin{tabular}{lcc}
\hline & $\mathrm{N}$ & $\%$ \\
\hline $0-29$ & 0 & 0.00 \\
$30-59$ & 0 & 0.00 \\
$60-89$ & 1 & 11.11 \\
$90-119$ & 4 & 44.45 \\
$120-139$ & 2 & 22.22 \\
$140-180$ & 2 & 22.22 \\
\hline
\end{tabular}

Respondents who taught animal processing and had a meat processing facility were asked if they had a custom or commercial license. Two respondents $(28.57 \%)$ indicated that they did not have a license. Two respondents $(28.57 \%)$ indicated that they had a custom license and three respondents (42.86\%) reported that they had a commercial license (see Table 16).

Table 16

Number of Meat Processing Facilities with a Custom or Commercial License $(N=7)$

\begin{tabular}{lcc}
\hline & $\mathrm{N}$ & $\%$ \\
\hline None & 2 & 28.57 \\
Custom & 2 & 28.57 \\
Commercial & 3 & 42.86 \\
\hline
\end{tabular}

Those who reported that they did not have a commercial license were then asked if they planned to obtain one. One respondent (16.67\%) indicated that they did plan to 
obtain a commercial license while five respondents $(83.33 \%)$ indicated that they did not (see Table 17).

Table 17

Number of Agricultural Educators who Plan to Obtain a Commercial License $(N=6)$

\begin{tabular}{lcc}
\hline & $\mathrm{N}$ & $\%$ \\
\hline No & 5 & 83.33 \\
Yes & 1 & 16.67 \\
\hline
\end{tabular}

Respondents who taught animal processing and had a meat processing facility were asked what other groups had they worked with cooperatively concerning their meat processing program. Two respondents $(100.00 \%)$ worked cooperatively with the farm service agency. One respondent (100.00\%) worked cooperatively with the Farm Bureau. Eight respondents (100.00\%) worked cooperatively with their Extension service. No one worked with the Department of Natural Resources (DNR) or the Cattleman's Association. Two respondents (100.00\%) worked with Hunter's Helping the Hungry (see Table 18). 
Table 18

Groups that Worked Cooperatively Within the Meat Processing Program $(N=11)$

\begin{tabular}{lcc}
\hline & $\mathrm{N}$ & $\%$ \\
\hline Farm Service Agency & 2 & 18.18 \\
Farm Bureau & 1 & 9.09 \\
Extension Service & 8 & 72.73 \\
DNR & 0 & 0.00 \\
Cattleman's Association & 0 & 0.00 \\
Hunter's Helping the Hungry & 2 & 18.18 \\
\hline
\end{tabular}

Respondents who taught animal processing and had a meat processing facility were asked if their agricultural education program supplied meat to the following places: local farmers' market, farm to school program, restaurants, and hospitals. One respondent (9.09\%) supplied meat to local restaurants. None of the respondents supplied meat to their local farmers' market, farm to school program, or hospitals (see Table 19). Table 19

Agricultural Education Programs who Supply Meat to Local Places $(N=11)$

\begin{tabular}{lll}
\hline & $\mathrm{N}$ & $\%$ \\
\hline Local Farmers' Market & 0 & 0.00 \\
Local Farm to School Program & 0 & 0.00 \\
Local Restaurants & 1 & 9.09 \\
Local Hospitals & 0 & 0.00 \\
\hline
\end{tabular}


Respondents who taught animal processing and had a meat processing facility were asked what value added processing techniques they implemented. Seven respondents (63.64\%) used jerky as a value added technique. Four respondents $(36.36 \%)$ prepared summer sausage. Eight respondents $(72.73 \%)$ processed breakfast sausage as a value added processing technique. Six respondents (54.55\%) prepared Italian sausage. None of the respondents reported that they implemented snack sticks as a value added processing technique (see Table 20).

Table 20

Value Added Processing Techniques Implemented by Agricultural Educators $(N=11)$

\begin{tabular}{lcc}
\hline & $\mathrm{N}$ & $\%$ \\
\hline Jerky & 7 & 63.64 \\
Summer Sausage & 4 & 36.36 \\
Breakfast Sausage & 8 & 72.73 \\
Italian Sausage & 6 & 54.55 \\
Snack Sticks & 0 & 0.00 \\
\hline
\end{tabular}

Respondents who taught animal processing and had a meat processing facility were asked what types of jobs were available in their area for this specific industry. Nine respondents $(81.82 \%)$ indicated that meat cutting jobs were available in their local area. Seven respondents $(63.64 \%)$ indicated the position of animal processor was available in their area. Eight respondents (72.73\%) indicated the position of animal slaughterer was available in their local area. None of the respondents indicated there were jobs in this specific industry in their local area (see Table 21). 
Table 21

Jobs Available in the Agricultural Educator's Local Area $(N=11)$

\begin{tabular}{lcc}
\hline & $\mathrm{N}$ & $\%$ \\
\hline Meat Cutter & 9 & 81.82 \\
Animal Processor & 7 & 63.64 \\
Animal Slaughterer & 8 & 72.73 \\
None & 0 & 0.00 \\
\hline
\end{tabular}

\section{Agricultural Education Students}

Respondents who taught animal processing and had a meat processing facility were asked how many students exhibited hams and bacons at the local, regional, and state level of the Ham, Bacon, and Egg Program. The average number of students who exhibited at the local level was 26.71 students $(\mathrm{SD}=19.59)$ with a minimum of five students competing and a maximum of 65 . The average number of students who exhibited at the regional level was 90.00 students $(\mathrm{SD}=4.24)$ with a minimum of six students and a maximum of 12 . The state level show and sale had a mean of 150.00 students $(\mathrm{SD}=7.07)$ with a minimum of five students and a maximum of 20 (see Table 22). 
Table 22

Number of Students who Exhibit Hams and Bacons

\begin{tabular}{lrcccc}
\hline & M & SD & Schools & Min & Max \\
\hline Local & 26.71 & 19.59 & 7 & 5 & 65 \\
Region & 90.00 & 4.24 & 2 & 6 & 12 \\
State & 150.00 & 7.07 & 4 & 5 & 20 \\
\hline
\end{tabular}

Respondents who taught animal processing and had a meat processing facility were asked to provide information on the students in their programs. The three categories included the number of students enrolled in the agricultural education program, number of students who used their meat processing facility, and the number of students who went through their program who became employed as a meat cutter each year. The average number of students enrolled in the agricultural education programs was 142.44 ( $\mathrm{SD}=60.68)$. The minimum number of students enrolled was 17 and the maximum was 260 . The mean number of students who used a meat processing facility was $61.33(\mathrm{SD}=37.86)$, the minimum was 20 , and the maximum was 120 . The mean number of student who became employed as meat cutter was $1.21(\mathrm{SD}=.57)$ with a minimum of one and a maximum of two (see Table 23). 
Table 23

Number of Students in the Program, Using the Facility, and Finding Employment

\begin{tabular}{lccccc}
\hline & M & SD & Schools & Min & Max \\
\hline Enrolled in Ag. Education & 142.44 & 60.68 & 9 & 75 & 260 \\
Use the Meat Facility & 61.33 & 37.86 & 9 & 20 & 120 \\
$\begin{array}{l}\text { Employed as a Meat } \\
\text { Cutter }\end{array}$ & 1.21 & .57 & 7 & 1 & 2 \\
\hline
\end{tabular}

Respondents who taught animal processing and had a meat processing facility were asked how many graduates who went through their meat processing program in the last five years had secured employment in animal processing. Three respondents $(33.33 \%)$ indicated 0-3 graduates found employment in animal processing. Five respondents (55.56\%) indicated 3-5 graduates secured employment in meat processing within the last five years. One respondent (11.11\%) had 5-10 graduates secure employment in meat processing. No one had more than 10 graduates in the last five years secure employment in animal processing (see Table 24)

Table 24

Number of Graduates Securing Employment in Animal Processing Over the Last Five Years $(N=9)$

\begin{tabular}{lcc}
\hline & $\mathrm{N}$ & $\%$ \\
\hline $0-3$ & 3 & 33.33 \\
$3-5$ & 5 & 55.56 \\
$5-10$ & 1 & 11.11 \\
$>10$ & 0 & 0.00 \\
\hline
\end{tabular}


Respondents who taught animal processing and had a meat processing facility were asked to rank their students on a Likert scale as novice, partial mastery, mastery, above mastery, and distinguished. Respondents ranked students who had some meat processing training, students who had taken one meat processing course, and students who had taken two meat processing courses. One respondent $(11.11 \%)$ ranked their students who had some meat processing training as novice, five respondents $(55.56 \%)$ ranked their students as having partial mastery, while three respondents (33.33\%) ranked their students as mastery. No respondents marked the above mastery or distinguished for their students with some meat processing training.

None of the respondents marked their students who had taken one meat processing course as novice. Two respondents $(25.00 \%)$ ranked their students who had taken one meat processing course as having partial mastery, four respondents $(50.00 \%)$ indicated students had mastery, while two respondents $(25.00 \%)$ reported students were above mastery. No one indicated that their students were distinguished if they had taken one meat processing course.

Two respondents reported that students with two meat processing courses were not applicable. Of the remaining six respondents no one indicated that their students were a novice if they had taken two meat processing courses. One respondent $(16.67 \%)$ indicated that their students who had taken two courses had partial mastery, one respondent $(16.67 \%)$ had chosen mastery, while three respondents $(50.00 \%)$ indicated that their students were above mastery and one respondent $(16.67 \%)$ indicated their students were distinguished (see Table 25). 
Table 25

Ranking of Meat Processing Skill Level of Students in Meat Processing Program

\begin{tabular}{|c|c|c|c|c|c|c|c|c|c|c|}
\hline & \multicolumn{2}{|c|}{ Novice } & \multicolumn{2}{|c|}{ P. Mastery } & \multicolumn{2}{|c|}{ Mastery } & \multicolumn{2}{|c|}{ A. Mastery } & \multicolumn{2}{|c|}{ Distinguished } \\
\hline & $\mathrm{N}$ & $\%$ & $\mathrm{~N}$ & $\%$ & $\mathrm{~N}$ & $\%$ & $\mathrm{~N}$ & $\%$ & $\mathrm{~N}$ & $\%$ \\
\hline Some Training & 1 & 11.11 & 5 & 55.56 & 3 & 33.33 & 0 & 0.00 & 0 & 0.00 \\
\hline One Course & 0 & 0.00 & 2 & 25.00 & 4 & 50.00 & 2 & 25.00 & 0 & 0.00 \\
\hline Two Courses & 0 & 0.00 & 1 & 16.67 & 1 & 16.67 & 3 & 50.00 & 1 & 16.67 \\
\hline
\end{tabular}

Respondents who teach animal processing and had a meat processing facility were asked to rank their highest performance level concerning processing different species of animals. Four respondents $(44.44 \%)$ had processed a beef and five respondents $(55.56 \%)$ possessed mastery. Two respondents $(22.22 \%)$ had processed pork and seven respondents $(77.78 \%)$ possessed mastery when processing pork. Two respondents $(22.22 \%)$ reported that seeing lamb processed was their highest performance level for the species. Five respondents $(55.56 \%)$ indicated that processing lamb was their highest performance level while two respondents $(22.22 \%)$ possessed mastery of processing lamb (see Table 26).

One respondent (12.50\%) reported having no knowledge on processing goats. One respondent $(12.50 \%)$ indicated that reading about processing goats was their highest performance level. Two respondents $(22.22 \%)$ had seen a goat processed and four respondents $(50.00 \%)$ had processed a goat. One respondent $(11.11 \%)$ did not possess knowledge on processing chickens. Three respondents $(33.33 \%)$ had seen a chicken processed. Three respondents $(33.33 \%)$ reported processing a chicken as their highest performance level and two respondents $(22.22 \%)$ possessed a mastery level for 
processing chickens. No one indicated that reading about processing chickens was their highest performance level. Two respondents $(22.22 \%)$ had no knowledge of processing turkeys. One respondent (11.11\%) had read about processing turkeys while three respondents $(33.33 \%)$ had seen it performed. One respondent $(11.11 \%)$ had processed a turkey and two respondents (22.22\%) possessed mastery.

Table 26

Animal Processing Performance Level of Agricultural Educators

\begin{tabular}{|c|c|c|c|c|c|c|c|c|c|c|}
\hline & \multicolumn{2}{|c|}{$\begin{array}{c}\text { No } \\
\text { Knowledge }\end{array}$} & \multicolumn{2}{|c|}{ Read About } & \multicolumn{2}{|c|}{$\begin{array}{c}\text { Seen } \\
\text { Performed }\end{array}$} & \multicolumn{2}{|c|}{$\begin{array}{l}\text { Performed } \\
\text { Myself }\end{array}$} & \multicolumn{2}{|c|}{$\begin{array}{l}\text { Possess } \\
\text { Mastery }\end{array}$} \\
\hline & $\mathrm{N}$ & $\%$ & $\mathrm{~N}$ & $\%$ & $\mathrm{~N}$ & $\%$ & $\mathrm{~N}$ & $\%$ & $\mathrm{~N}$ & $\%$ \\
\hline Beef & 0 & 0.00 & 0 & 0.00 & 0 & 0.00 & 4 & 44.44 & 5 & 55.56 \\
\hline Swine & 0 & 0.00 & 0 & 0.00 & 0 & 0.00 & 2 & 22.22 & 7 & 77.78 \\
\hline Sheep & 0 & 0.00 & 0 & 0.00 & 2 & 22.22 & 5 & 55.56 & 2 & 22.22 \\
\hline Goats & 1 & 12.50 & 1 & 12.50 & 2 & 25.00 & 4 & 50.00 & 0 & 0.00 \\
\hline Chickens & 1 & 11.11 & 0 & 0.00 & 3 & 33.33 & 3 & 33.33 & 2 & 22.22 \\
\hline Turkey & 2 & 22.22 & 1 & 11.11 & 3 & 33.33 & 1 & 11.11 & 2 & 22.22 \\
\hline Deer & 0 & 0.00 & 0 & 0.00 & 0 & 0.00 & 4 & 44.44 & 5 & 55.56 \\
\hline Fish & 1 & 12.50 & 0 & 0.00 & 3 & 37.50 & 3 & 37.50 & 1 & 12.50 \\
\hline Other & 2 & 50.00 & 0 & 0.00 & 0 & 0.00 & 1 & 25.00 & 1 & 25.00 \\
\hline
\end{tabular}

Four respondents (44.44\%) had processed venison while five respondents $(55.56 \%)$ possessed mastery of processing venison. One respondent $(12.50 \%)$ indicated that they had no knowledge on processing fish. Three respondents (37.50\%) indicated that they had seen fish processed. Three respondents (37.50\%) had processed a fish and one respondent (12.50\%) possessed mastery. Two respondents $(50.00 \%)$ had no 
knowledge on "other" animals. One respondent $(25.00 \%)$ had processed an "other" animal and one respondent (25.00\%) possessed. mastery of processing an "other" animal (see Table 27).

Respondents who taught animal processing and had a meat processing facility were asked to provide information on where they acquired the knowledge and skill to process each type of species. One respondent (11.11\%) indicated that their high school agricultural education provided the knowledge and skill to process beef. Three respondents $(33.33 \%)$ learned how to process beef through a college course. One respondent (11.11\%) acquired the knowledge and skill to process beef through work experience. Four respondents (44.44\%) indicated that they acquired the knowledge and skill to process beef while teaching agricultural education (see Table 27).

Two respondents (22.22\%) had acquired the knowledge and skill to process pork from their high school agricultural education program. Two respondents $(22.22 \%)$ had attained the knowledge of processing pork through a college course. One respondent (11.11\%) had learned the skill through work experience and four respondents (44.44\%) had acquired the skill while teaching agricultural education.

One respondent (11.11\%) attained knowledge and skill to process lamb from their high school agricultural education program. Four respondents (44.44\%) had acquired this skill through a college course. One respondent (11.11\%) had attained the knowledge and skill to process lamb through work experience and three respondents (33.33\%) had attained the skill while teaching agricultural education.

Two respondents $(25.00 \%)$ indicated that they had acquired the knowledge and skill to process a goat through their home farm. One respondent (12.50\%) indicated that 
they had learned to process a goat through work experience. Three respondents $(37.50 \%)$ reported that they had gained the knowledge and skill while teaching agricultural education. Two respondents had reported that the source of their knowledge and skill for processing goats was not applicable.

Four respondents $(50.00 \%)$ reported that they had gained the knowledge and skill to process chickens from their home farm. Two respondents $(25.00 \%)$ indicated that they had gained the skill to process chickens through a college course. One respondent $(12.50 \%)$ had gained the skill through work experience and one respondent $(12.50 \%)$ had gained the skill while teaching agricultural education. No respondents indicated that they have attained the skills through their high school agricultural education program.

Two respondents $(25.00 \%)$ reported that they had gained the knowledge and skill to process turkeys through their home farm. One respondent $(12.50 \%)$ had acquired the skill to process turkeys through a college course and one respondent $(12.50 \%)$ had acquired the skill through work experience. Two respondents $(25.00 \%)$ had gained the knowledge and skill while teaching agricultural education and two respondents $(25.00 \%)$ reported that the source of knowledge and skill to process turkey was not applicable. No one indicated that the source came from their high school agricultural education program.

Two respondents $(25.00 \%)$ acquired the knowledge and skill of processing venison from their high school agricultural education program. Three respondents $(37.50 \%)$ indicated that the source of knowledge came from their home farm. One respondent $(12.50 \%)$ have gained the knowledge and skill through work experience and two respondents $(25.00 \%)$ reported that the source of knowledge occurred while teaching 
agricultural education. No one indicated that a college course was a source of knowledge for processing venison.

Table 27

Agricultural Educator's Source of Knowledge and Skill of Animal Processing

\begin{tabular}{|c|c|c|c|c|c|c|c|c|c|c|c|c|}
\hline & \multicolumn{2}{|c|}{$\begin{array}{l}\text { H.S. Ag. } \\
\text { Education }\end{array}$} & \multicolumn{2}{|c|}{$\begin{array}{l}\text { Home } \\
\text { Farm }\end{array}$} & \multicolumn{2}{|c|}{$\begin{array}{l}\text { College } \\
\text { Course }\end{array}$} & \multicolumn{2}{|c|}{$\begin{array}{c}\text { Work } \\
\text { Experience }\end{array}$} & \multicolumn{2}{|c|}{$\begin{array}{l}\text { While } \\
\text { Teaching } \\
\text { Ag }\end{array}$} & \multicolumn{2}{|c|}{ NA } \\
\hline & $\mathrm{N}$ & $\%$ & $\mathrm{~N}$ & $\%$ & $\mathrm{~N}$ & $\%$ & $\mathrm{~N}$ & $\%$ & $\mathrm{~N}$ & $\%$ & $\mathrm{~N}$ & $\%$ \\
\hline Beef & 1 & 11.11 & 0 & 0.00 & 3 & 33.33 & 1 & 11.11 & 4 & 44.44 & 0 & 0.00 \\
\hline Swine & 2 & 22.22 & 0 & 0.00 & 2 & 22.22 & 1 & 11.11 & 4 & 44.44 & 0 & 0.00 \\
\hline Sheep & 1 & 11.11 & 0 & 0.00 & 4 & 44.44 & 1 & 11.11 & 3 & 33.33 & 0 & 0.00 \\
\hline Goats & 0 & 0.00 & 2 & 25.00 & 0 & 0.00 & 1 & 12.50 & 3 & 37.50 & 2 & 25.00 \\
\hline Chickens & 0 & 0.00 & 4 & 50.00 & 2 & 25.00 & 1 & 12.50 & 1 & 12.50 & 0 & 0.00 \\
\hline Turkey & 0 & 0.00 & 2 & 25.00 & 1 & 12.50 & 1 & 12.50 & 2 & 25.00 & 2 & 25.00 \\
\hline Deer & 2 & 25.00 & 3 & 37.50 & 0 & 0.00 & 1 & 12.50 & 2 & 25.00 & 0 & 0.00 \\
\hline Fish & 1 & 12.50 & 2 & 25.00 & 1 & 12.50 & 1 & 12.50 & 2 & 25.00 & 1 & 12.50 \\
\hline Other & 0 & 0.00 & 0 & 0.00 & 0 & 0.00 & 0 & 0.00 & 2 & 66.67 & 1 & 33.33 \\
\hline
\end{tabular}

One respondent $(12.50 \%)$ reported attaining knowledge of processing fish through their high school agricultural education program. Two respondents (25.00\%) reported that the source of knowledge came from their home farm. One respondent (12.50\%) had acquired the skill through a college course and one respondent (12.50\%) had attained the knowledge and skill through work experience. Two respondents (25.00\%) indicated that their source of knowledge occurred while teaching agricultural education and two respondents (25.00\%) indicated the question did not apply. 
Two respondents (66.67\%) reported that they had gained knowledge and skill of processing "other" animals while teaching agriculture. One respondent $(33.33 \%)$ indicated that processing "other" animals did not apply (see Table 27).

Respondents who taught animal processing and had a meat processing facility were asked to describe their interest in processing different species of animal using a Likert scale. Two respondents (22.22\%) ranked their interest in teaching beef processing as high and seven respondents (77.78\%) ranked their interest as very high. Two respondents $(22.22 \%)$ ranked their interest in teaching pork processing as high and seven respondents (77.78\%) reported their interest as very high. Four respondents (44.44\%) indicated that they had a medium interest in teaching how to process lamb, while two respondents (22.22\%) ranked their interest as high and three respondents $(33.33 \%)$ ranked their interest as very high.

Three respondents (33.33\%) ranked their interest in teaching how to process goats as very low, three respondents $(33.33 \%)$ ranked their interest as medium, two respondents $(22.22 \%)$ as high, and one respondent (11.11\%) ranked their interest as high. Four respondents $(50.00 \%)$ ranked their interest in teaching how to process chickens as very low, two respondents $(25.00 \%)$ ranked their interest as medium and two respondents (25.00\%) ranked their interest in teaching the subject matter as high. Five respondents $(62.50 \%)$ ranked their interest in teaching how to process turkeys as low and three respondents $(37.50 \%)$ ranked their interest as medium.

One respondent $(12.50 \%)$ ranked their interest in teaching venison processing as very low, two respondents $(25.00 \%)$ ranked their interest as medium, four respondents $(50.00 \%)$ ranked their interest as high, and one respondent (12.50\%) ranked their interest 
as very high. Four respondents $(50.00 \%)$ ranked their interest in teaching fish processing as very low, two respondents $(25.00 \%)$ ranked their interest as medium, and two respondents $(25.00 \%)$ ranked their interest in teaching fish processing as high. One respondent (33.33\%) ranked their interest in teaching "other" animal processing as very low and two respondents (66.67\%) ranked their interest as high (see Table 28$)$.

Table 28

Agricultural Educators Interest in Teaching Animal Processing

\begin{tabular}{lcccccccccc}
\hline & \multicolumn{2}{l}{ Very Low } & \multicolumn{2}{l}{ Low } & \multicolumn{2}{l}{ Medium } & \multicolumn{2}{l}{ High } & \multicolumn{2}{c}{ Very High } \\
\cline { 2 - 10 } & $\mathrm{N}$ & $\%$ & $\mathrm{~N}$ & $\%$ & $\mathrm{~N}$ & $\%$ & $\mathrm{~N}$ & $\%$ & $\mathrm{~N}$ & $\%$ \\
\hline Beef & 0 & 0.00 & 0 & 0.00 & 0 & 0.00 & 2 & 22.22 & 7 & 77.78 \\
Swine & 0 & 0.00 & 0 & 0.00 & 0 & 0.00 & 2 & 22.22 & 7 & 77.78 \\
Sheep & 0 & 0.00 & 0 & 0.00 & 4 & 44.44 & 2 & 22.22 & 3 & 33.33 \\
Goats & 3 & 33.33 & 0 & 0.00 & 3 & 33.33 & 2 & 22.22 & 1 & 11.11 \\
Chickens & 4 & 50.00 & 0 & 0.00 & 2 & 25.00 & 2 & 25.00 & 0 & 0.00 \\
Turkeys & 5 & 62.50 & 0 & 0.00 & 3 & 37.50 & 0 & 0.00 & 0 & 0.00 \\
Deer & 1 & 12.50 & 0 & 0.00 & 2 & 25.00 & 4 & 50.00 & 1 & 12.50 \\
Fish & 4 & 50.00 & 0 & 0.00 & 2 & 25.00 & 2 & 25.00 & 0 & 0.00 \\
Other & 1 & 33.33 & 0 & 0.00 & 0 & 0.00 & 2 & 66.67 & 0 & 0.00 \\
\hline
\end{tabular}

Respondents who taught animal processing and had a meat processing facility were asked to describe the teaching method(s) used to teach processing of different food animal species. Three respondents $(33.33 \%)$ indicated that they demonstrated how to process a beef and six respondents $(66.67 \%)$ reported that they had the students practice how to process a beef. Two respondents $(22.22 \%)$ used the demonstration teaching 
method to teach how to process pork and seven respondents (77.78\%) had students practice processing pork. One respondent (11.11\%) used a movie/video to teach how to process lamb. Five respondents $(55.56 \%)$ demonstrated how to process lamb and three respondents $(33.33 \%)$ had students practice how to process lamb.

One respondent (11.11\%) did not teach goat processing, one respondent (11.11\%) discussed how to process a goat, one respondent (11.11\%) used book assignments, one respondent (11.11\%) used movies/videos to teach the subject matter, four respondents (44.44\%) demonstrated how to process a goat, and one respondent (11.11\%) had the students practice goat processing. Two respondents $(25.00 \%)$ did not teach chicken processing. One respondent $(12.50 \%)$ used the discussion teaching method and one respondent (12.50\%) used movies/videos to teach the material. Two respondents (25.00\%) used demonstrations to teach chicken processing and two respondents $(25.00 \%)$ had the students practice poultry processing. Two respondents $(25.00 \%)$ did not teach turkey processing. One respondent $(12.50 \%)$ used discussion to teach turkey processing and one respondent $(12.50 \%)$ used book assignments. Two respondents $(25.00 \%)$ used movies/videos and two respondents $(25.00 \%)$ demonstrated how to process turkeys.

Two respondents $(25.00 \%)$ did not teach venison processing. Three respondents $(37.50 \%)$ demonstrated how to process venison and three respondents $(37.50 \%)$ had students practice processing venison. Three respondents (37.50\%) did not teach fish processing. Two respondents (25.00\%) indicated that they used movie/videos to teach fish processing and three respondents (37.50\%) had students practice the process. Two respondents $(66.67 \%)$ demonstrated how to process "other" animals and one respondent (33.33\%) had students practice processing "other" products (see Table 29). 
Table 29

Teaching Methods Used by Agricultural Educators for Animal Processing

\begin{tabular}{|c|c|c|c|c|c|c|c|c|c|c|c|c|}
\hline & \multicolumn{2}{|c|}{$\begin{array}{l}\text { Did Not } \\
\text { Teach }\end{array}$} & \multicolumn{2}{|c|}{ Discussion } & \multicolumn{2}{|c|}{$\begin{array}{l}\text { Book } \\
\text { Assign. }\end{array}$} & \multicolumn{2}{|c|}{$\begin{array}{l}\text { Movie } \\
\text { Videos }\end{array}$} & \multicolumn{2}{|c|}{$\begin{array}{l}\text { Demon- } \\
\text { stration }\end{array}$} & \multicolumn{2}{|c|}{$\begin{array}{l}\text { Students } \\
\text { Practiced }\end{array}$} \\
\hline & $\mathrm{N}$ & $\%$ & $\mathrm{~N}$ & $\%$ & $\mathrm{~N}$ & $\%$ & $\mathrm{~N}$ & $\%$ & $\mathrm{~N}$ & $\%$ & $\mathrm{~N}$ & $\%$ \\
\hline Beef & 0 & 0.00 & 0 & 0.00 & 0 & 0.00 & 0 & 0.00 & 3 & 33.33 & 6 & 66.67 \\
\hline Swine & 0 & 0.00 & 0 & 0.00 & 0 & 0.00 & 0 & 0.00 & 2 & 22.22 & 7 & 77.78 \\
\hline Sheep & 0 & 0.00 & 0 & 0.00 & 0 & 0.00 & 1 & 11.11 & 5 & 55.56 & 3 & 33.33 \\
\hline Goats & 1 & 11.11 & 1 & 11.11 & 1 & 11.11 & 1 & 11.11 & 4 & 44.44 & 1 & 11.11 \\
\hline Chickens & 2 & 25.00 & 1 & 12.50 & 0 & 0.00 & 1 & 12.50 & 2 & 25.00 & 2 & 25.00 \\
\hline Turkey & 2 & 25.00 & 1 & 12.50 & 1 & 12.50 & 2 & 25.00 & 2 & 25.00 & 0 & 0.00 \\
\hline Deer & 2 & 25.00 & 0 & 0.00 & 0 & 0.00 & 0 & 0.00 & 3 & 37.50 & 3 & 37.50 \\
\hline Fish & 3 & 37.50 & 0 & 0.00 & 0 & 0.00 & 2 & 25.00 & 0 & 0.00 & 3 & 37.50 \\
\hline Other & 0 & 0.00 & 0 & 0.00 & 0 & 0.00 & 0 & 0.00 & 2 & 66.67 & 1 & 33.33 \\
\hline
\end{tabular}

Respondents who taught animal processing and had a meat processing facility were asked if they were interested in attending professional development activities on different meat processing topics in their region. Five respondents $(45.45 \%)$ indicated that they were interested in attending activities in their region involving the laws. Four respondents $(36.36 \%)$ indicated that they were interested in attending professional development activities on the safe handling of red meat. Three respondents $(27.27 \%)$ were interested in attending professional development activities on the safe handling of poultry. Six respondents $(54.55 \%)$ were interested in attending activities on Hazard Analysis and Critical Control Points (HACCP) in their region. Five respondents $(45.45 \%)$ were interested in red meat fabrication and three respondents $(27.27 \%)$ would attend 
activities in their region on poultry fabrication. Six respondents $(54.55 \%)$ would attend activities on curing technology and four respondents $(36.36 \%)$ were interested in venison processing if it was held in their region. Four respondents $(36.36 \%)$ were interested in attending professional development activities on the topic of customer relations. Three respondents $(27.27 \%)$ were interested in learning more about fish processing and handling. Six respondents (54.55\%) were interested in attending professional development activities in their region on fresh and cured sausage manufacturing (see Table 30).

Table 30

Agricultural Teacher's Interest in Attending Professional Development Opportunities in $\operatorname{Region}(N=11)$

\begin{tabular}{llc}
\hline & $\mathrm{N}$ & $\%$ \\
\hline Laws and Regulations & 5 & 45.45 \\
Safe Handling of Red Meat & 4 & 36.36 \\
Safe Handling of Poultry & 3 & 27.27 \\
HACCP & 6 & 54.55 \\
Red Meat Fabrication & 5 & 45.45 \\
Poultry Fabrication & 3 & 27.27 \\
Curing Technology & 6 & 54.55 \\
Venison Processing & 4 & 36.36 \\
Customer Relations & 4 & 36.36 \\
Fish Processing and Handling & 3 & 27.27 \\
Fresh and Cured Sausage Man. & 6 & 54.55 \\
Other Useful Information & 0 & 0.00 \\
\hline
\end{tabular}


Respondents who teach animal processing and had a meat processing facility were asked to express their interest in attending professional development activities on different meat processing topics held at West Virginia University. Two respondents $(18.18 \%)$ were interested in attending activities at West Virginia University on laws and regulations and two respondents $(18.18 \%)$ were interested in attending activities on the safe handling of red meat. Two respondents $(18.18 \%)$ were also interested in attending activities at West Virginia University on the safe handling of poultry. One individual (9.09\%) reported interest in attending activities that focused on Hazard Analysis and Critical Control Points (HACCP). Two respondents (18.18\%) were interested in attending professional development activities on red meat fabrication. Poultry fabrication was a topic that three respondents $(27.27 \%)$ were interested in attending at West Virginia University. Two respondents (18.18\%) expressed interest in attending topics on curing technology and one respondent (9.09\%) expressed interest in attending professional development activities on venison processing. One respondent (9.09\%) also reported interest in attending activities on customer relations at the university. Two respondents $(18.18 \%)$ were interested in attending activities that focused on fish handling and processing. Two respondents $(18.18 \%)$ were interested in attending professional development activities on fresh and cured sausage manufacturing none of the respondents $(0.00 \%)$ expressed interest in attending professional development activities on other useful information (see Table 31). 
Table 31

Agricultural Teacher's Interest in Attending Professional Development Opportunities at $W V U(N=11)$

\begin{tabular}{llc}
\hline & $\mathrm{N}$ & $\%$ \\
\hline Laws and Regulations & 2 & 18.18 \\
Safe Handling of Red Meat & 2 & 18.18 \\
Safe Handling of Poultry & 2 & 18.18 \\
HACCP & 1 & 9.09 \\
Red Meat Fabrication & 2 & 18.18 \\
Poultry Fabrication & 3 & 27.27 \\
Curing Technology & 2 & 18.18 \\
Venison Processing & 1 & 9.09 \\
Customer Relations & 1 & 9.09 \\
Fish Processing and Handling & 2 & 18.18 \\
Fresh and Cured Sausage Man. & 2 & 18.18 \\
Other Useful Information & 0 & 0.00 \\
\hline
\end{tabular}

Respondents who taught animal processing and had a meat processing facility were asked if they had flexibility in their curriculum to include more instruction on animal processing. Seven respondents $(77.78 \%)$ reported that they did have flexibility in the curriculum and two respondents $(22.22 \%)$ did not have flexibility in the curriculum (see Table 32). 
Table 32

Agricultural Educators' Flexibility in their Curriculum to Include More Animal

Processing $(N=9)$

\begin{tabular}{lcc}
\hline & $\mathrm{N}$ & $\%$ \\
\hline No & 2 & 22.22 \\
Yes & 7 & 77.78 \\
\hline
\end{tabular}

\section{Agriculture Teachers who do not Teach Animal Processing}

Respondents who did not teach animal processing were asked if they were interested in starting a meat processing program. Twenty four respondents $(55.81 \%)$ were not interested in starting a meat processing program and 19 respondents $(44.19 \%)$ were interested in starting a meat processing program (see Table 33).

Table 33

Agricultural Educator's Interest in Starting a Meat Processing Program $(N=43)$

\begin{tabular}{lcc}
\hline & $\mathrm{N}$ & $\%$ \\
\hline No & 24 & 55.81 \\
Yes & 19 & 44.19 \\
\hline
\end{tabular}

Respondents who did not teach animal processing were asked what their main concerns were with starting a meat processing facility/program. Twenty-nine respondents $(64.44 \%)$ indicated that no funds were their main concern with starting a meat processing program. Twenty-two respondents $(48.89 \%)$ indicated that no time was a main concern and five respondents $(11.11 \%)$ were not interested in starting a meat processing program. Thirteen respondents $(28.89 \%)$ indicated that the lack of knowledge 
on animal processing was a hindrance for starting a meat processing program. Twelve respondents $(26.67 \%)$ reported that a lack of knowledge on the rules and regulations were a main concern with starting a meat processing program (see Table 34).

Table 34

Agricultural Educator's Concerns with Starting a Meat Processing Facility/Program (N $=45)$

\begin{tabular}{lcc}
\hline & $\mathrm{N}$ & $\%$ \\
\hline No Funds & 29 & 64.44 \\
Not Enough Time & 22 & 48.89 \\
No Interest & 5 & 11.11 \\
Lack Knowledge on Processing & 13 & 28.89 \\
Lack Knowledge on Rules and Reg. & 12 & 26.67 \\
\hline
\end{tabular}

Respondents who did not teach animal processing were asked to rank their background in animal processing. Four respondents $(9.30 \%)$ ranked their background as weak. Five respondents (11.63\%) ranked their background as below average, 14 respondents $(32.56 \%)$ indicated that their background was average, and 15 respondents $(34.88 \%)$ reported that their background was strong. Five respondents $(11.63 \%)$ ranked their interest in animal processing as very strong (see Table 35). 
Table 35

Agricultural Educators Background in Animal Processing $(N=43)$

\begin{tabular}{lcc}
\hline & $\mathrm{N}$ & $\%$ \\
\hline Weak & 4 & 9.30 \\
Below Average & 5 & 11.63 \\
Average & 14 & 32.56 \\
Strong & 15 & 34.88 \\
Very Strong & 5 & 11.63 \\
\hline
\end{tabular}

Respondents who did not teach animal processing were asked if they would be interested in attending a workshop sponsored by West Virginia University to learn more about animal processing. Thirty-three respondents (76.74\%) reported that they were interested in attending a workshop and 10 respondents $(23.26 \%)$ were not interested in attending a workshop (see Table 36).

Table 36

Agricultural Educator's Interest in Attending Workshops Sponsored by WVU $(N=43)$

\begin{tabular}{lcc}
\hline & $\mathrm{N}$ & $\%$ \\
\hline No & 10 & 23.26 \\
Yes & 33 & 76.74 \\
\hline
\end{tabular}

\section{Agricultural Education Teachers who do not have a Meat Processing Facility}

Respondents who taught animal processing but did not have a meat processing facility were asked how they teach animal processing information. One respondent $(50.00 \%)$ used lecture, one respondent $(50.00 \%)$ used movies, one respondent $(50.00 \%)$ 
used hands on activities, and both respondents (100.00\%) used the demonstration teaching method to teach animal processing (see Table 37).

Table 37

Teaching Methods of Animal Processing without a Meat Facility $(N=2)$

\begin{tabular}{lcc}
\hline & $\mathrm{N}$ & $\%$ \\
\hline Lecture & 1 & 50.00 \\
Book Assignments & 0 & 0.00 \\
Movies & 1 & 50.00 \\
Demonstration & 2 & 100.00 \\
Hands on Activities & 1 & 50.00 \\
\hline
\end{tabular}

Respondents who taught animal processing but did not have a meat processing facility were asked where they teach animal processing. Two respondents (100.00\%) indicated that they used the classroom, one respondent (50.00\%) used their shop, and one respondent (50.00\%) went outside to teach the material (see Table 38).

Table 38

Teaching Locations of Animal Processing without a Meat Facility $(N=2)$

\begin{tabular}{llc}
\hline & $\mathrm{N}$ & $\%$ \\
\hline Classroom & 2 & 100.00 \\
Shop & 1 & 50.00 \\
Outside & 1 & 50.00 \\
\hline
\end{tabular}

Respondents who taught animal processing but did not have a meat processing facility were asked what animals they process. Two respondents (100.00\%) reported 
processing beef, two respondents $(100.00 \%)$ reported processing pork, and one respondent $(50.00 \%)$ reported processing lamb, and one respondent $(50.00 \%)$ processed venison (see Table 39).

Table 39

Animals Processed without a Meat Facility $(N=2)$

\begin{tabular}{lcc}
\hline & $\mathrm{N}$ & $\%$ \\
\hline Beef & 2 & 100.00 \\
Swine & 2 & 100.00 \\
Sheep & 1 & 50.00 \\
Goats & 0 & 0.00 \\
Chickens & 0 & 0.00 \\
Fish & 0 & 0.00 \\
Deer & 1 & 50.00 \\
Turkeys & 0 & 0.00 \\
\hline
\end{tabular}

Respondents who taught animal processing but did not have a meat processing facility were asked if they were interested in building a meat processing lab. Two respondents $(100.00 \%)$ indicated they were interested in building a meat processing lab (see Table 40).

Table 40

Agricultural Educator's Interest in Building a Meat Processing Lab $(N=2)$

\begin{tabular}{lcr}
\hline & N & $\%$ \\
\hline No & 0 & 0.00 \\
Yes & 2 & 100.00 \\
\hline
\end{tabular}


Respondents who taught animal processing but did not have a meat processing facility were asked their concerns with starting a meat processing facility/program. Two respondents $(100.00 \%)$ indicated they did not have the funds to start a program (see

Table 41).

Table 41

Concerns with Starting a Meat Processing Facility/Program $(N=2)$

\begin{tabular}{lcc}
\hline & N & $\%$ \\
\hline No Funds & 2 & 100.00 \\
Not Enough Time & 0 & 0.00 \\
No Interest & 0 & 0.00 \\
Lack Knowledge on Processing & 0 & 0.00 \\
Lack Knowledge on Rules and Reg. & 0 & 0.00 \\
\hline
\end{tabular}

Respondents who taught animal processing but did not have a meat processing facility were asked to rank their background in animal processing. One respondent (50.00\%) ranked their background as strong and one respondent (50.00\%) ranked their background in animal processing as very strong (see Table 42).

Table 42

Agricultural Educators Background in Animal Processing $(N=2)$

\begin{tabular}{lcc}
\hline & $\mathrm{N}$ & $\%$ \\
\hline Weak & 0 & 0.00 \\
Below Average & 0 & 0.00 \\
Average & 0 & 0.00 \\
Strong & 1 & 50.00 \\
Very Strong & 1 & 50.00 \\
\hline
\end{tabular}


Respondents who taught animal processing but did not have a meat processing facility were asked if they were interested in attending a meat processing workshop sponsored by West Virginia University. Two respondents (100.00\%) indicated that they were interested in attending the workshops (see Table 43).

Table 43

Agricultural Educator's Interest in Attending Meat Processing Workshops Sponsored by $W V U(N=2)$

\begin{tabular}{lcc}
\hline & $\mathrm{N}$ & $\%$ \\
\hline No & 0 & 0.00 \\
Yes & 2 & 100.00 \\
\hline
\end{tabular}




\section{CHAPTER V}

\section{Summary, Conclusions, and Recommendations}

\section{Purpose of Study}

The purpose of this study was to determine the types of meats processing equipment and facilities that exist in West Virginia's high school agricultural education programs. In addition, training needs of the agricultural education instructors will be determined. Variables that were investigated included: (a) meat processing facilities in agricultural education programs (b) meat processing equipment (c) number of students that use the meat processing facility (d) teaching methods used to deliver meat processing material (e) teachers performance levels on processing animals (f) views on professional development opportunities hosted by West Virginia University and (g) types of professional development that is needed.

The study provided information regarding the level of interest in attending workshops and adult education classes to help improve the instruction of their students. This information will be valuable to agricultural education teachers, agricultural education students, state staff, and West Virginia University faculty to help educate teachers to prepare students to enter employment.

\section{Objective of the Study}

The objectives of the study are reflected in the following research questions:

1. How many agricultural education programs in West Virginia have a meat processing facility?

2. How much space is available in the meat facilities?

3. What meat processing equipment is used in the program? 
4. What species of food animals are students taught to process?

5. How was the program funded?

6. What are the performance levels for those teachers who teach animal processing?

7. What teaching methods are being used to teach meat processing materials?

8. How many days per school year is each program's facility used?

9. What kind of meat processing, professional development opportunities would agricultural teachers find useful?

\section{Limitations of the Study}

The study was limited to agricultural education program in West Virginia. All currently employed agricultural teachers were included in this study.

\section{Summary}

The accessible population consisted of 103 current agricultural education teachers in West Virginia. Fifty-eight questionnaires (56.31\%) were completed. Of the respondents, $13(22.41 \%)$ taught animal processing and of those 13 respondents, 11 had a meat processing facility. No one indicated that the meat processing facility that they had access to was not located at their school.

Of those respondents, who taught animal processing and had a meat processing facility, the majority of the respondents were male (88.89\%). The largest group of respondents (44.44\%) indicated they had been teaching for more than 25 years. The largest group of respondents (44.44\%) also indicated that they were 41-50 years old. The majority of those respondents' $(77.78 \%)$ school was located in a rural farm area.

Respondents who taught animal processing and had a meat processing facility were asked questions on their meat processing facility. Most of the respondents $(81.8 \%)$ 
were the only teacher in their agricultural education department that used the meat processing facility. The local Board of Education was the biggest funder of animal processing facilities $(\mathrm{M}=153,750.00)$. Processing fees for food animals $(63.63 \%)$ and selling meat products produced in the lab $(63.64 \%)$ were the two most popular ways to fund the day-to-day operation of the meat processing facility. Swine $(\mathrm{M}=70.22)$, deer $(\mathrm{M}=61.25)$, and beef $(\mathrm{M}=22.44)$ were the most popular species of animal for a program to process. All respondents used their facility at least 60 days out of the 180 day school year and that the majority of respondents (44.44\%) were using the facility 90-119 days. Three respondents $(42.86 \%)$ had a commercial license and only one respondent $(16.67 \%)$ was interested to obtain one.

Respondents who taught animal processing and had a meat processing facility were also asked questions about the students who used their facility. Respondents indicated that more students exhibited hams and bacons for the Ham, Bacon, and Egg Program at the local level $(M=26.71)$ than regionally $(M=90.00)$ or at the state show $(\mathrm{M}=150.00)$. Less than half of the students enrolled in agricultural education $(\mathrm{M}=142.44)$ used the meat processing facility ( $M=61.33)$. Furthermore, the majority of programs (55.56\%) had only 3-5 graduates secure employment in the animal processing field over the last five years. Even though there was a low rate of students finding employment in this field, respondents indicated that students received proper training and skills. If a student had taken at least one meat processing course, their processing skill was at least partial mastery, and the majority of students were ranked as having mastery skills $(50.00 \%)$. Furthermore, if a student had taken two meat processing courses, most were ranked as above mastery $(37.5 \%)$. 
Respondents who taught animal processing and had a meat processing facility were asked to indicate their highest level of proficiency in processing different food animal species of. Pork processing $(77.78 \%)$ had the largest percentage of respondents indicate that they possessed mastery performance level followed by beef $(55.56 \%)$ and venison (55.56\%). Most respondents learned to process beef (44.44\%) and pork (44.44\%) while they taught agricultural education, and the source of knowledge for venison $(37.50 \%)$ came from the respondent's home farm. When the respondents were asked to rank their interest in teaching animal processing beef $(77.78 \%)$ and swine $(77.78 \%)$ were the two species that most respondents ranked very high. Furthermore, pork $(77.78 \%)$ had the largest number of respondents indicating they had students practice processing the animal followed closely by beef $(66.67 \%)$.

Respondents who taught animal processing and had a meat processing facility were asked if they would be interested in attending professional development activities in the region or at West Virginia University. There was a higher interest in attending the activities in the region. The categories that respondents were most likely to attend were fresh and cured sausage manufacturing (36.36\%), curing technology $(36.36 \%)$, and Hazard Analysis and Critical Control Points (HACCP) (36.36\%).

Of the respondents who did not teach animal processing, almost half indicated that they were interested in starting a meat processing program $(44.19 \%)$. The greatest concern with starting a meat processing facility/program was lack of funds $(64.44 \%)$ followed by lack of time (48.89\%). The largest group of respondents $(34.88 \%)$ indicated that their background in animal processing was strong. Additionally, most of the 
respondents $(76.74 \%)$ were interested in attending meat processing workshops sponsored by West Virginia University.

Of the respondents who taught animal processing but did not have a meat processing facility both respondents $(100.00 \%)$ indicated that they were interested in starting a meat processing facility. The two respondents' (100.00\%) main concern with starting a facility was the lack of funds. Both respondents $(100.00 \%)$ were already processing beef and pork and both respondents (100.00\%) were using the classroom to teach animal processing.

\section{Conclusions}

Based on the results of this study, the following conclusions were made

1. A low percentage of agricultural educators currently teach animal processing.

2. Nearly half of the agricultural education students enrolled in programs with meat processing facilities are using the facilities as a part of their education.

3. The students enrolled in a meat processing course receive hands on training and skills of at least partial mastery or above.

4. There are food animal processing jobs in the local area of all agricultural education teachers in the state.

5. Teachers are more likely to attend professional development activities held in their local region than at West Virginia University.

6. Agricultural education teachers that are currently teaching meat processing are interested in attending professional development activities on fresh and cured sausage manufacturing, curing technology, and Hazard Analysis and Critical Control Points (HACCP). 
7. Many teachers, who currently do not have a meat processing program, are interested in starting one.

8. Lack of funds is the biggest inhibitor of teachers starting a meat processing program.

9. Many teachers, who currently do not teach animal processing, are interested in attending workshops on meat processing.

10. Most teachers, who already teach animal processing, gained their knowledge while teaching agricultural education.

11. Meat processing facilities in agricultural education programs in West Virginia vary greatly in size, space, and amount and type of equipment.

12. Many of the meat processing facilities were used by only one agricultural education teacher, even if the teacher was in a multi-teacher department.

\section{Recommendations}

The researcher offers the following recommendations based on the results of the study.

1. Since many agricultural educators indicated that nearly half of their students used the meat processing facility, it would be important to conduct a follow up study to inquire about the students' opinion on their ability to process meat.

2. The study showed that, on average, students who take a meat processing course receive hands on training and skills of partial mastery level or above. Furthermore, the agriculture teachers indicated that there are food animal processing jobs in their local area. Therefore a follow up study should be conducted on the students' career choices and why the meat processing field has not been a popular selection. 
3. There was a higher interest in attending professional development activities in each region of the state, than at West Virginia University. Professional development activities should be held in each region of the state to meet teacher's needs. The topics that should first be covered are fresh and cured sausage manufacturing, curing technology, and Hazard Analysis and Critical Control Points (HACCP) since these topics are of greatest interest.

4. A series of meat processing beginner workshops should be sponsored by West Virginia University. Many respondents were interested in starting a meat processing program and attending workshops on meat processing. Most teachers who already teach animal processing gained their knowledge while teaching agriculture. These workshops would give those who do not teach this subject the opportunity to learn through an instructor and gain hands on skills to teach their students.

5. State meat processing facilities vary greatly in size, space, and amount of equipment. There should be a workshop held for those who do not have a meat processing facility on how to construct one with as few inputs as possible. The workshop should provide teachers with what is required when building one, how to construct it as cost efficient as possible, and what kind of processing they can accomplish with their facility.

6. Lack of funds was the biggest inhibitor of starting a meat processing program. A newsletter or email should be sent to agricultural education teachers in the state explaining how other programs raised the funds to start a program. Also group 
discussions during workshops and professional development activities would be beneficial.

7. A high percentage of meat processing programs were used by only one agricultural education teacher. Respondents indicated that they did not teach animal processing because the other agricultural teacher in their program already taught the subject matter. A study should be conducted on why multi-teacher programs are not sharing their teaching resources. 


\section{REFERENCES}

American Farm Bureau Federation (2013). Food and Farm Facts. Washington D.C.: American Farm Bureau Federation Public Relations Department

Ary, D., Jacobs, L., \& Sorensen, C. (2009). Introduction to research in education. (8th ed.). Belemont, CA: Wadsworth.

Dickenson, E., Joseph, S., \& Ward, J. (n.d.). Confronting challenges in the local meat industry: Focus on the Pioneer Valley of Western Massachusetts. Retrieved from http://www.buylocalfood.org/local-meat-processing-study/

Dillman, D. A. (2000). Mail and internet surveys: The tailored design method. $2^{\text {nd }}$ Edition. New York: John Wiley Co.

Duncan, D. W., Ricketts, J. C., Peake, J. B., \& Uessler, J. (2005). Identifying teaching and learning in-service needs of Georgia agriculture teachers. Proceedings of the $32^{\text {nd }}$ American Association of Agricultural Educators Research Conference, (pp. 91-102), San Antonio, TX.

Ewing, J., Gill, B., Radhakrishna, R., \& Clark, R. (n.d.). Identifying in-service needs of secondary agricultural teachers by content area. Retrieved from http://www.public.iastate.edu/ laanan/ACTER/pdfs/InService_Needs.pdf

Fravel, P.(1989). A history of agricultural education in South Carolina with an emphasis on the public school program. Retrieved from http://scholar.lib.vt.edu/theses/available/etd-04242004202220/unrestricted/FravelDissertation.pdf

Holcomb, R., Flynn, K., \& Kenkel , P. (2012). A feasibility template for small, multispecies meat processing plants. Journal of Extension, 50(5). Retrieved from http://www.joe.org/joe/2012october/tt11.php

Illinois Agricultural Education. (n.d.). High school ag ed is. Retrieved from http://www.agriculturaleducation.org/Ag-Ed Programs/High-School Ag Ed Is

Joint Economic Committee. (2013). The economic contribution of America's farmers and the importance of agricultural exports. Retrieved from http://www.jec.senate.gov/public/?a=Files.Serve\&File_id=266a0bf3-5142-4545b806-ef9fd78b9c2f

Leopold Center for Sustainable Agriculture. (2011). A feasibility study for the creation of a meat processing training program in Iowa. Retrieved from http://www.leopold.iastate.edu/sites/default/files/grants/M2009-28.pdf

Living History Farm. (n.d.). Shrinking farm numbers. Retrieved from http://www.livinghistoryfarm.org/farminginthe50s/life_11.html 
Martinez, S., et al. 2010. Local food systems: Concepts, impacts, and issues. United States Department of Agriculture: Economic Research Report, No. 97

Moeini, H. (2008). Identifying needs: A missing part in teaching training programs. International Journal of Media, Technology and Lifelong Learning, 4(1) Retrieved on from http://www.seminar.net/images/stories/vol4-issue1/moiniidentifyingneeds.pdf

National Ag Day, (n.d.) For educators and students. Retrieved from http://www.agday.org/education/careers.php

National Association of Agricultural Educators. (n.d.). About ag education. Retrieved from http://www.naae.org/teachag/about-ag-education.php

Patterson, S. (n.d.). Smith-Hughes Act of 1917 (PL 347). Retrieved from http://jschell.myweb.uga.edu/history/legis/smithughes.htm

Robinson, J. P. Shaver, P. R., \& Wrightsman, L. S. (1991). Criteria for scale selection and evaluation. In J. P. Robinson, P. R. Shaver, \& L. S. Wrightsman (Eds.). Measures of personality and social psychological attitudes (pp. 1-16) New York: Academic Press.

Schneider, M., \& Francis, C., (2005). Marketing locally produced foods: Consumer and farmer opinions in Washington County, Nebraska. Renewable Agriculture and Food Systems, 20, 252-260. doi:10.1079/RAF2005114

Schroeder, A. R. (2013). Local Food, Local Jobs: Job Growth and Creation in the. Retrieved from http://www.mass.gov/eea/docs/agr/boards-commissions/mwafood-report-03062013-screen.pdf

Stewart, S. (2014). Farm-to-School initiative connects farmers with students. Retrieved from http://pocahontastimes.com/farm-to-school-initiative-connects-farmers-withstudents/

The National FFA Organization. (n.d.). Agricultural education. Retrieved from https://www.ffa.org/about/whoweare/Pages/AgriculturalEducation.aspx

The State Journal (2013) Ag Commissioner Walt Helmick going whole hog to develop economic opportunities for agriculture. Retrieved from http://www.statejournal.com/story/23770292/ag-commissioner-walt-helmick-isgoing-whole-hog-to-develop-economic-opportunities-for-wv-in-the-field-ofagriculture

The Washington Post. (2013). Feds say W.Va.'s growing local-food movement may become a model for the rest of Appalachia. Retrieved from http://articles.washingtonpost.com/2013-05-22/business/39428047_1_u-sdepartment-local-foods-jams 
United States Department of Agriculture. (2007). Table 2. Market Value of Agricultural Products Sold Including Landlord's Share and Direct Sales: 2007 and 2002. Retrieved from http://www.agcensus.usda.gov/Publications/2007/Full_Report/Volume_1,_Chapte r_1_State_Level/West_Virginia/st54_1_002_002.pdf

United States Department of Agriculture. (2013). Food expenditures overview. Retrieved from http://www.ers.usda.gov/data-products/food-expenditures.aspx

United States Environmental Protection Agency. (n.d.).Demographics. Retrieved from http://www.epa.gov/oecaagct/ag101/demographics.html

Virginia Department of Education. (2013). Preparing students for successful transition to college and careers the changing face of Virginia agriculture. Retrieved from http://www.doe.virginia.gov/instruction/career_technical/agriculture/agriculture_e ducation_report.pdf

West Virginia Department of Agriculture. (2012). Student ham and bacon programs growing in popularity. Retrieved from http://www.wvagriculture.org/news_releases/2012/2-17-12-e.html

West Virginia Department of Agriculture. (2013). 70th state FFA ham, bacon, and egg auction set for March 11. Retrieved from http://www.wv.gov/news/Pages/70thStateFFAHam,Bacon,andEggAuctionSetfor March.aspx

West Virginia Department of Education (n.d.). Agriculture, Food, and Natural Resources. Retrieved from http://careertech.k12.wv.us/SkillsetsAG.html

West Virginia HUB. (2013). WashPo: "Feds say W. Va's growing local food movement may become a model for the rest of Appalachia". . Retrieved from http://www.wvhub.org/wvffc/news/washpo-feds-say-w-vas-growing-local-foodmovement-may-become-model-rest-appalachia

West Virginia HUB. (n.d.). New initiative will invest in food and farm businesses across 17 West Virginia counties. . Retrieved from http://www.wvhub.org/wvffc/news/new-initiative-will-invest-food-and-farmbusinesses-across-17-west-virginia-counties

West Virginia University. (2014) Detailed Course Information: FDST 365-Muscle Foods Technology. Retrieved from:https://star.wvu.edu/pls/starprod/bwckctlg.p_disp_course_detail?cat_term_i $\mathrm{n}=201408 \&$ subj_code_in $=$ FDST\&crse_numb_in $=365$ 
APPENDIX A:

Questionnaire 


\section{The Current Status of Meat Processing Programs\&nbsp;in Agricultural}

The Current Status of Meat Processing Programs in Agricultural Education in West Virginia

Dear W Agricultural Education Instructor:

A successful meat processing facility requires a lot of effort and skills. As an agricultural education teacher, you understand the importance of training in this area. We need your input on the current status of your meat program, facilities, methods of teaching meat processing and your interest in professional development activities to improve your animal and food processing knowledge and skills.

I am Eleanor Porter, a graduate student in Agricultural and Extension Education at West Virginia University. Under the direction of my advisor, Dr. Harry N. Boone, Jr., I am conducting a research study to determine the ways meats facilities are utilized in the agricultural education curriculum and if West Virginia teachers with a meats facility would be interested in working in collaboration with WWU to receive more hands on training and skills in the animal processing field. The results of this study will be used to prepare a thesis to partially fulfill the requirements for a Master of Science degree in Agricultural and Extension Education. The results will provide insight to West Virginia University on the types of processional development activities that would be beneficial to agricultural educators in the state.

Participation in this research is completely voluntary and will take approximately twenty minutes of your time. All responses will be held as confidential as possible. You may skip any question that you are uncomfortable answering or may quit at any point and submit the partially completed survey. The responses of the survey will be reported in a summary format and individual responses will not be identifiable. Please answer questions honestly and to the best of your abilities. There is no penalty if you choose not to participate.

After completing the survey click on the submit button. West Virginia University's Institutional Review Board (IRB) has approved this study and the acknowledgement of this research is on file.

We would like to thank you in advance for taking time to participate in this survey. Please submit the completed survey by Monday, March 10, 2014. If you have questions please contact Eleanor Porter at (eporter3@mix.wvu.edu) or Dr. Harry Boone at 304-293-5451 (harry. boone@mail.wvu.edu).

If you have any questions about the questionnaire please contact:

Eleanor Porter

Graduate Student

Agricultural and Extension Education

eporter3@mix.mvu.edu

\section{Do you teach animal processing?}
Ores
No 


\section{The Current Status of Meat Processing Programs\&nbsp;in Agricultural}

2. Does your program have access to a meats processing facility?

Yres

No

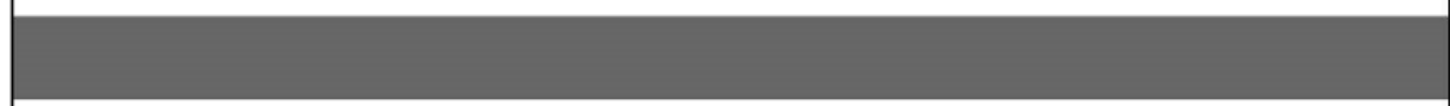

3. Is the meat facility located at your school?

Yes

No

4. Who is in charge of your meat facility? (Name and title of individual)

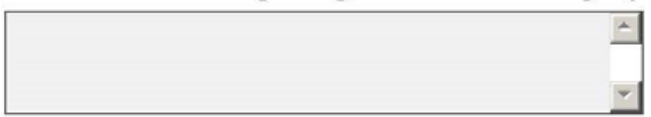

5. How many teachers are in your agricultural education program?

$\mathrm{O}_{1}$

$\mathrm{O}_{2}$

$\mathrm{O}_{3}$

${ }_{4}$

6. How many teachers in your agricultural education program use the meat facility for teaching purposes?

$\mathrm{O}_{1}$

$\mathrm{O}_{2}$

$\mathrm{O}_{3}$

$\mathrm{O}_{4}$ 


\section{The Current Status of Meat Processing Programs\&nbsp;in Agricultural}

7. Please identify the number and source of each of the following meat processing items you possess. (Only answer the choices that apply)
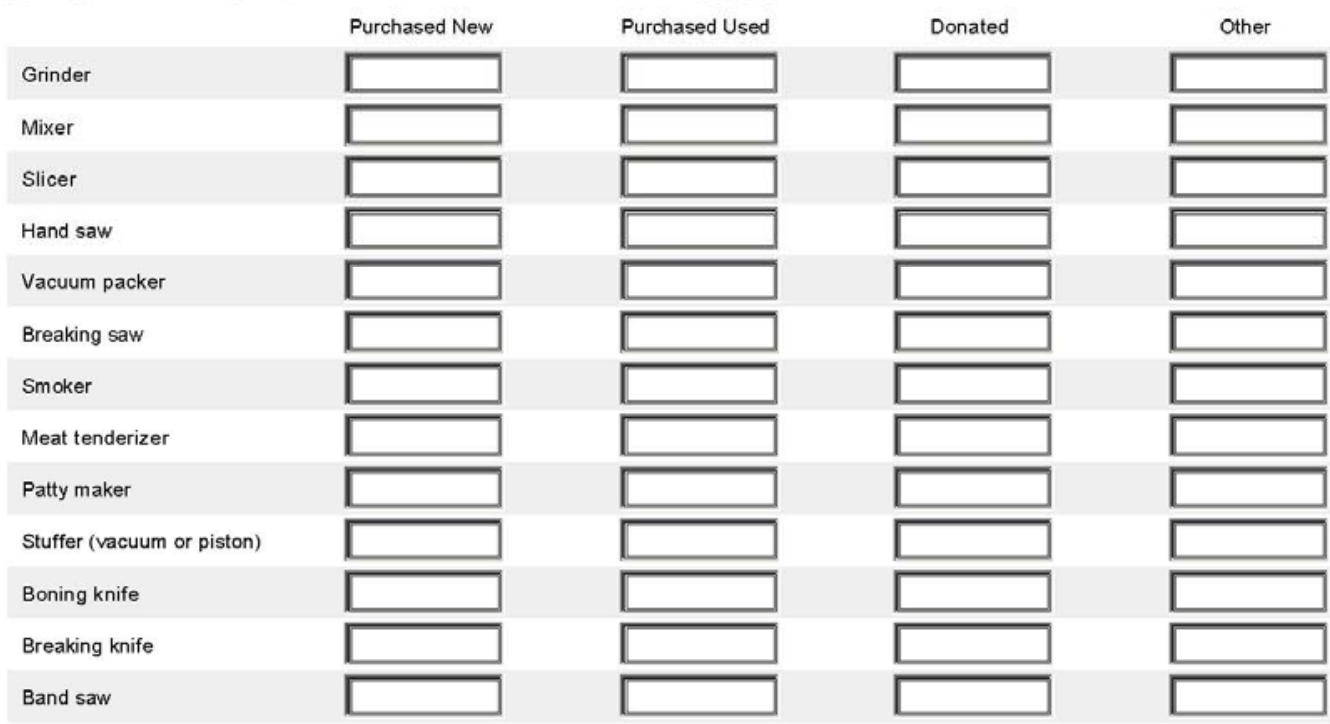

Other (please specify)

8. What is the square footage of your meat facility's floor space?(Please fill in)

9. What is the approximate square footage of each of your walk-in coolers? (Please fill in) Cooler 1

Cooler 2

Cooler 3

Cooler 4

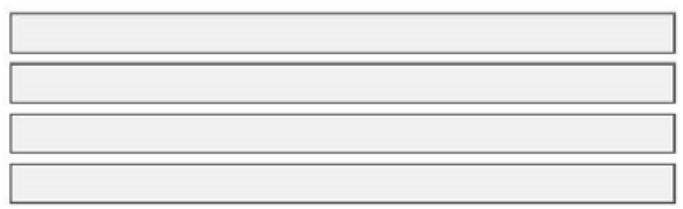

10. What is the approximate square footage of each of your walk-in freezers? (Please fill in)

Freezer 1

Freezer 2

Freezer 3

Freezer 4

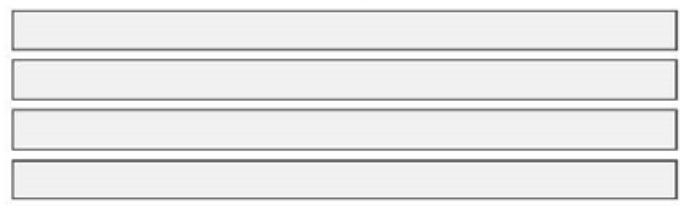




\section{The Current Status of Meat Processing Programs\&nbsp;in Agricultural}

11. How many additional chest or upright freezers are used by the meat processing facility?

One

Two

Three

Four

More than Four

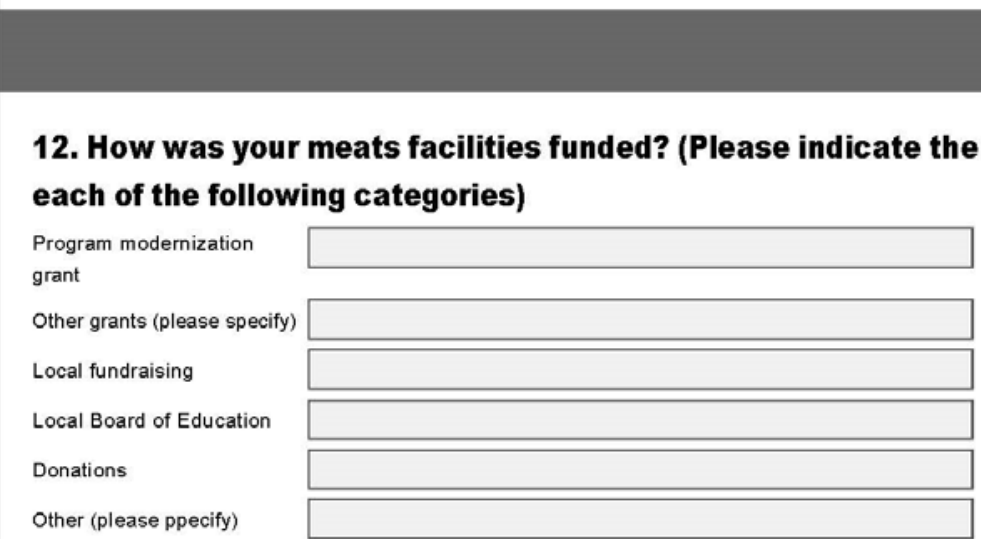

13. How is the day-to-day operation of the meat processing facility funded? (Check all that apply)

Processing fees for

domestic animals

Processing fees for wild

game

Selling meat products

processed in the lab

County Board of Education

FFA Chapter

FFA Alumni Chapter

Other (please specify)

Day-to-day operation

$\bigcirc$

0

0

0 


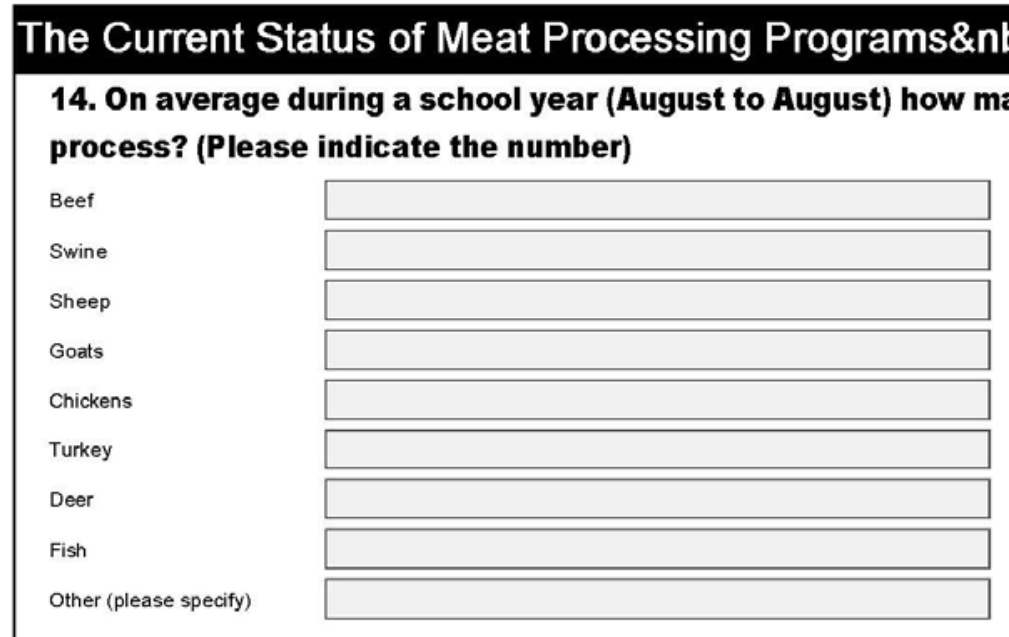

15. Out of the 180 school days, how many school days do you use your meat facilities?

0.29

30-59

60-89

90-119

120-139

140-180

16. How many students exhibit hams and bacons in the Ham, Bacon and Egg Program? (Please indicate the number for each level)

Local

Regional

State

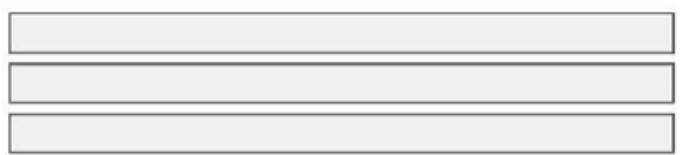

17. What kind of license do you have?

$\bigcirc$ Commercial

Custom

None 
The Current Status of Meat Processing Programs\&nbsp;in Agricultural

18. Do you plan to obtain a commercial license?

Yes

No

19. What type(s) of animal processing classes have you taught for adult audiences over the past year? (Please indicate the course title(s))

a)

b)

c)

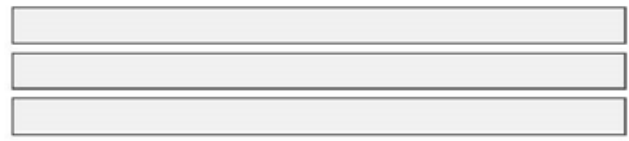

20. Please indicate the number of students for each of the categories listed below.

Students enrolled in

agricultural education

program

Students who use the meat

processing facilities

21. What course(s) do you teach that utilizes the meats facility? (Please indicate the course name(s))

a)

b)

c)

d)

e)

f)

22. Please select the answer that most accurately describes the average performance level of each group of students in your agricultural education program?

Students with some meat
processing training




\section{The Current Status of Meat Processing Programs\&nbsp;in Agricultural}

23. Over the past five years how many graduates that went through your meat processing program secured employment in animal processing?

0-3

3-5

5-10

$\bigcirc>10$

24. On average, how many students that go through your meat processing program each year are employed as a meat cutter? (Please indicate the number)

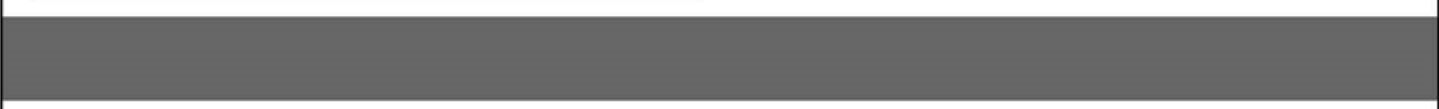

25. Please select the answer the most accurately describes your highest performance for each of the listed categories.

Processing Beef
Processing Swine
Processing Sheep
Processing Goats
Processing Chickens
Processing Deer
Processing Fish

Please specify the "other products" category 


\section{The Current Status of Meat Processing Programs\&nbsp;in Agricultural}

26. Please select the answer that most accurately describes where you acquired the knowledge and skills to perform at the level described in the previous question.

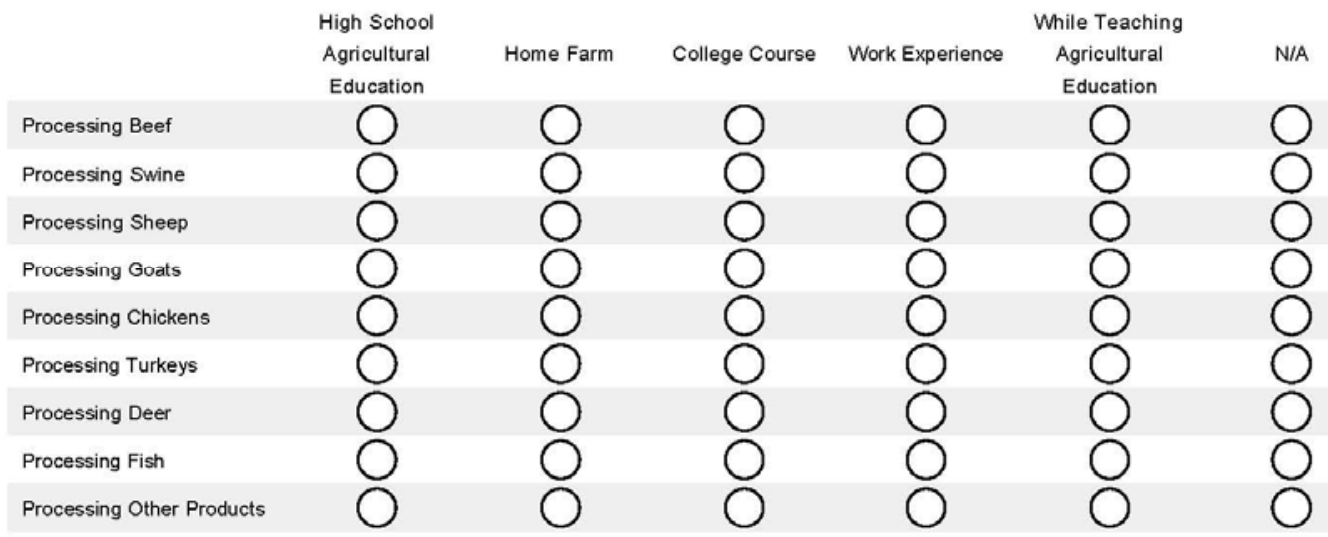

27. Please select the answer that most accurately describes your interest in teaching the skill.

Processing Beef
Processing Swine
Processing Sheep
Processing Goats
Processing Chickens
Processing Turkeys
Processing Deer
Processing Fish
Processing Other Products
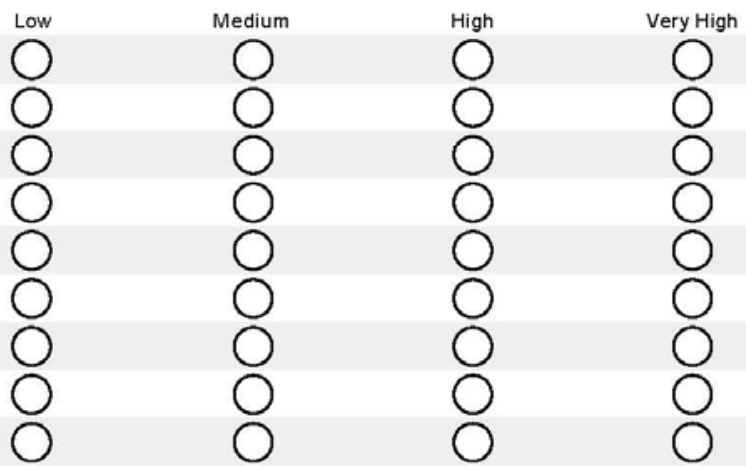


\section{The Current Status of Meat Processing Programs\&nbsp;in Agricultural}

28. Please select the answer that most accurately describes the teaching method you use to teach the skill.

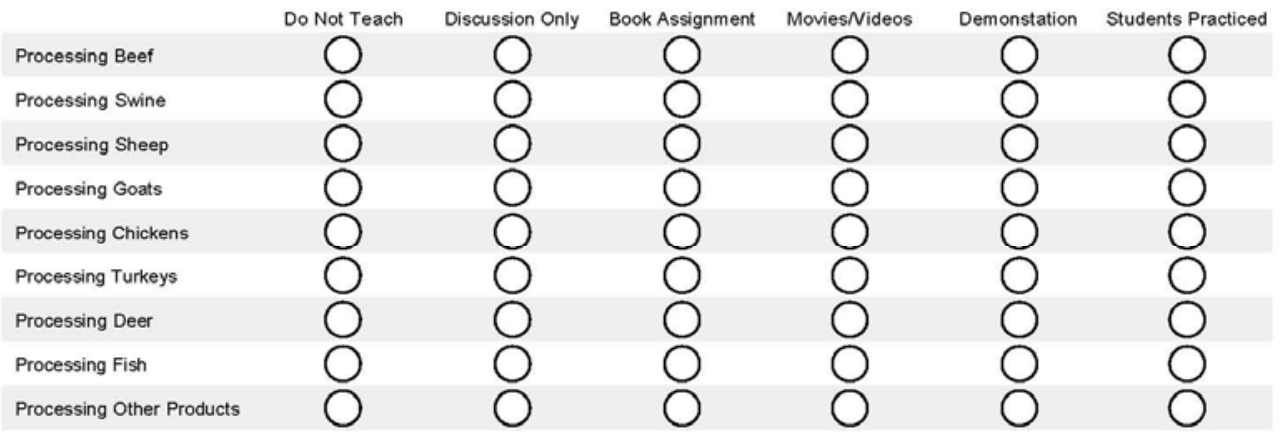

29. Would you be interested in professional development activities on the following topics offered in your region or on campus at West Virginia University? (Select all that apply)

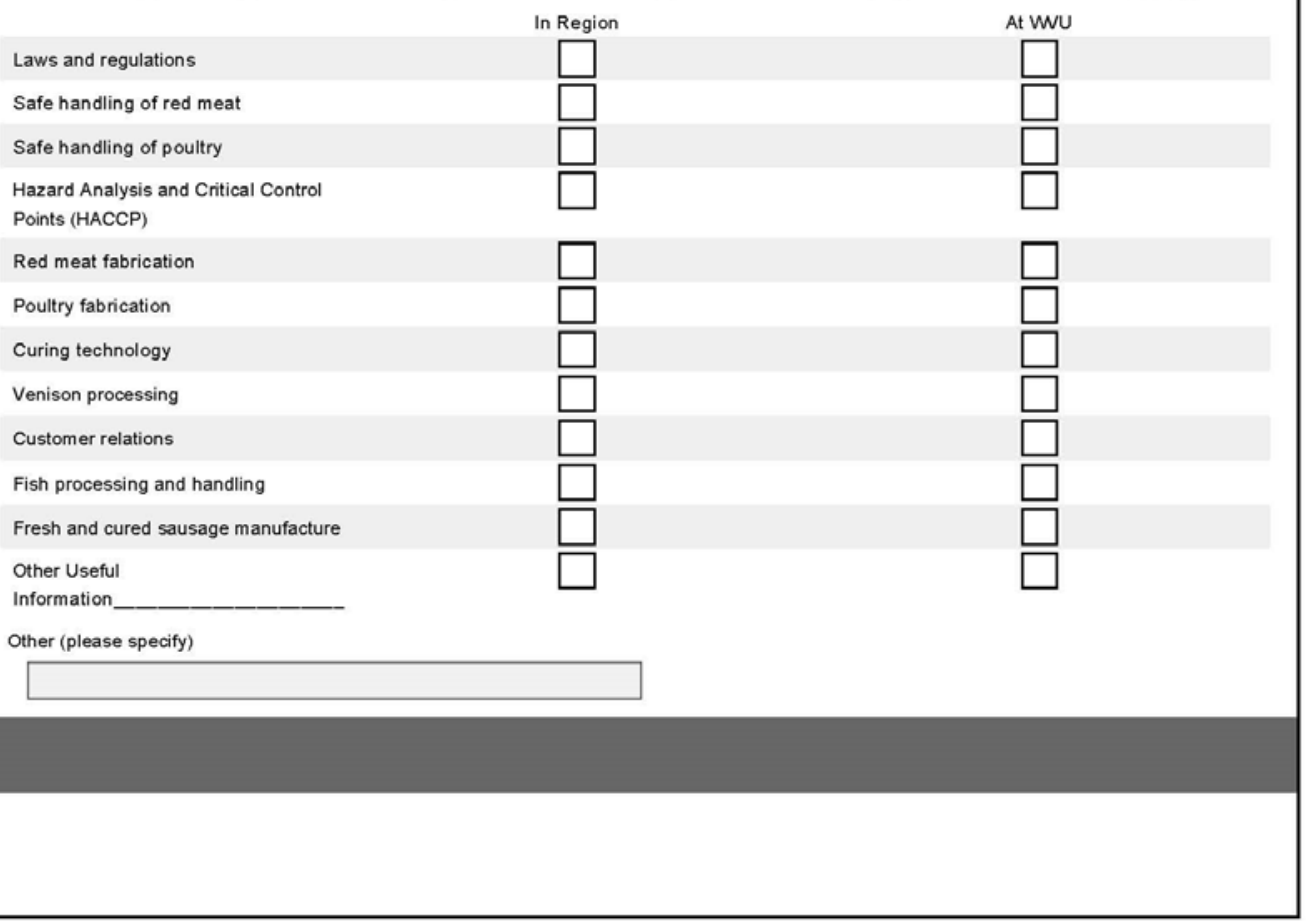

Page 9 


\section{The Current Status of Meat Processing Programs\&nbsp;in Agricultural}

30. Is there flexibility in your curriculum to include more instruction on animal processing?

Yes

№

31. What are the non-meat processing classes that you teach? (Please provide the course names)

a)
b)
c)
d)
e)
f)
g)

32. Within your meat processing program, what other groups have you worked cooperatively? (Check all that apply)
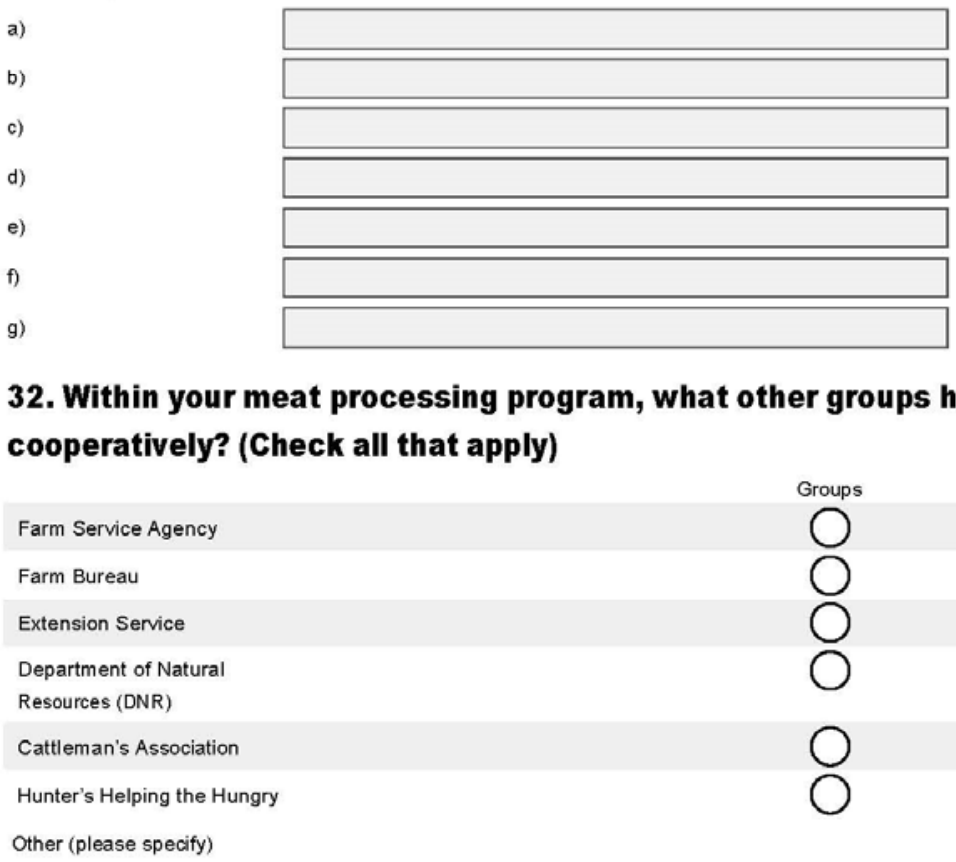

(20)

33. To which of the following does your agricultural education program supply meat products? (Check all that apply)

Local farmers market
Local farm to school
programs
Local restaurants
Local hospitals

Other (please specify) 


\section{The Current Status of Meat Processing Programs\&nbsp;in Agricultural}

34. How many of your students supply meat to the following places? (Please indicate the number)

Local farmers market

Local farm to school

program

Local restaurants

Local hospitals

Other (please specify)
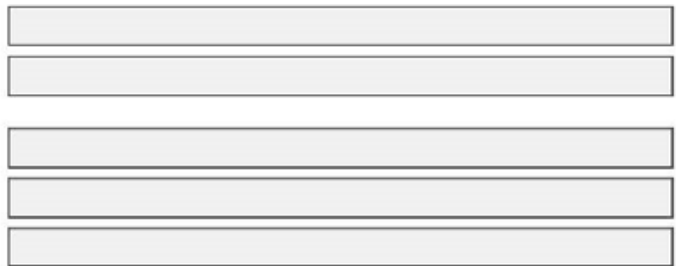

35. Which of the following value-added processing techniques do you implement? (Check all that apply)

$\square$ Jerky

$\square$ Summer sausage

$\square$ Breakfast sausage

$\square$ Italian sausage

$\square$ Snack sticks

Other (please specify)

36. What types of jobs are available in your area for this specific industry? (Check all that apply)

$\square$ Meat Cutter

$\square$ Animal Processor

$\square$ Animal Slaughterer

$\square$ None

Other (please specify)

37. How would you describe the area where your school is located?

Rural farm

Rural non-farm

Suburban

Urban 


\section{The Current Status of Meat Processing Programs\&nbsp;in Agricultural}

38. How many years of teaching experience do you have (including this year)?

$1-5$ years

6.10 years

11-15 years

16-20 years

21-25 years

More than 25 years

39. How old are you?

21-30 years

31-40 years

41-50 years

51-60 years

60 years and over

40. What is your gender?

Male

Female

41. What is the highest level of education that you have obtained?

Bachelor's

Bachelor's +15

Master's

Master's +15

Master's +30

Master's +45

Doctorate

42. Are you interested in starting a meat processing program?

$O$ yes

No 


\section{The Current Status of Meat Processing Programs\&nbsp;in Agricultural}

43. What are your main concerns with starting a meat processing facility/program? (Check all that apply)

$\square$ No funds

$\square$ Not enough time

$\square$ No interest

$\square$ Lack of knowledge on processing

$\square$ Lack of knowledge on the rules and regulation

Other (please specify)

44. How would you rate your background in animal processing?

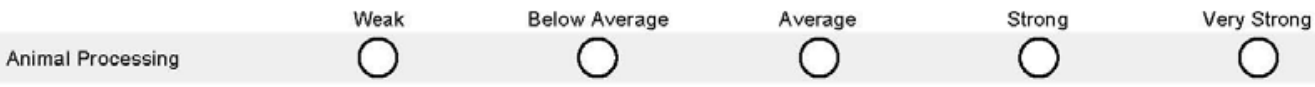

45. Would you be interested in attending a workshop sponsored by West Virginia University to learn more about animal processing?

Yes

No

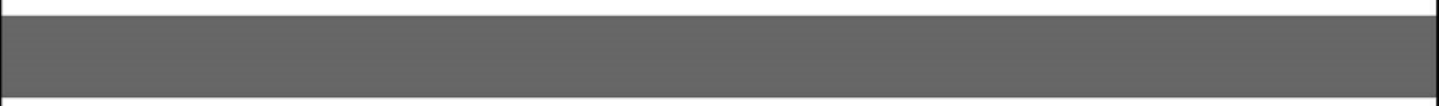

46. How do you teach meat processing information? (Check all that apply)

$\square$ Lecture
$\square$ Book assignments
$\square$ Movies
$\square$ Demonstration
$\square$ Hands on activities

Other (please specify) 
The Current Status of Meat Processing Programs\&nbsp;in Agricultural

47. Where do you teach meat processing?(Check all that apply)

$\square$ Classroom

$\square$ Shop

$\square$ Outside

Other (please specify)

48. What animals do you process? (Check all that apply)

$\square$ Beef

$\square$ Swine

$\square$ sheep

$\square$ Goats

$\square$ Chickens

$\square$ Fish

$\square$ Deer

$\square$ Turkeys

Not applicable

Other (please specify)

49. Are you interested in building a meat processing lab?

Yres

No

50. What are your main concerns with starting a meat processing facility/program? (Check all that apply)

$\square$ No funds

$\square$ Not enough time

$\square$ No interest

$\square$ Lack of knowledge on processing

$\square$ Lack of knowledge on the rules and regulation

Other (please specify) 


\section{The Current Status of Meat Processing Programs\&nbsp;in Agricultural}

51. How would you rate your background in animal processing?

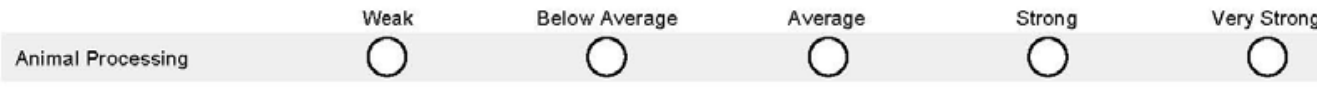

52. Would you be interested in attending a workshop sponsored by West Virginia University to learn more about animal processing?

Yres

No 
APPENDIX B:

Initial Email 
March 3, 2014

Dear Agricultural Education Teachers:

A successful meat processing facility requires a lot of effort and skills. As an agricultural education teacher, you understand the importance of training in this area. We need your input on the current status of your meat program, facilities, methods of teaching meat processing and your interest in professional development activities to improve your animal and food processing knowledge and skills.

I am Eleanor Porter, a graduate student in Agricultural and Extension Education at West Virginia University. Under the direction of my advisor, Dr. Harry N. Boone, Jr., I am conducting a research study to determine the ways meats facilities are used in the agricultural education curriculum and if West Virginia teachers with a meats facility would be interested in working in collaboration with WVU to receive more hands on training and skills in the animal processing field. The results of this study will be used to prepare a thesis to partially fulfill the requirements for a Master of Science degree in Agricultural and Extension Education. The results will provide insight to West Virginia University on the types of processional development activities that would be beneficial to agricultural educators in the state.

Participation in this research is completely voluntary and will take approximately twenty minutes of your time. All responses will be held as confidential as possible. You may skip any question that you are uncomfortable answering or may quit at any point and submit the partially completed survey. The responses of the survey will be reported in a summary format and individual responses will not be identifiable. Please answer questions honestly and to the best of your abilities. There is no penalty if you choose not to participate.

The online survey can be accessed through the following site:https://www.surveymonkey.com/s/ZW2SSR6

After completing the survey click on the "done" button. West Virginia University's Institutional Review Board (IRB) has approved this study and the acknowledgement of this research is on file.

We would like to thank you in advance for taking time to participate in this survey. Please submit the completed survey by Monday, March 10, 2014. If you have questions please contact Eleanor Porter at (eporter3@mix.wvu.edu) or Dr. Harry Boone at 304293-5451(harry.boone@mail.wvu.edu).

Sincerely,

Eleanor Porter

Graduate Student
Harry N. Boone, Jr., Ph.D.

Professor and Chair 
APPENDIX C:

Cover Letter 
March 3, 2014,

Dear Agricultural Education Teachers:

A successful meat processing facility requires a lot of effort and skills. As an agricultural education teacher, you understand the importance of training in this area. We need your input on the current status of your meat program, facilities, methods of teaching meat processing and your interest in professional development activities to improve your animal and food processing knowledge and skills.

I am Eleanor Porter, a graduate student in Agricultural and Extension Education at West Virginia University. Under the direction of my advisor, Dr. Harry N. Boone, Jr., I am conducting a research study to determine the ways meats facilities are used in the agricultural education curriculum and if West Virginia teachers with a meats facility would be interested in working in collaboration with WVU to receive more hands on training and skills in the animal processing field. The results of this study will be used to prepare a thesis to partially fulfill the requirements for a Master of Science degree in Agricultural and Extension Education. The results will provide insight to West Virginia University on the types of processional development activities that would be beneficial to agricultural educators in the state.

Participation in this research is completely voluntary and will take approximately twenty minutes of your time. All responses will be held as confidential as possible. You may skip any question that you are uncomfortable answering or may quit at any point and submit the partially completed survey. The responses of the survey will be reported in a summary format and individual responses will not be identifiable. Please answer questions honestly and to the best of your abilities. There is no penalty if you choose not to participate.

The online survey can be accessed through the following site: https://www.surveymonkey.com/s/ZW2SSR6. After completing the survey click on the "done" button. West Virginia University's Institutional Review Board (IRB) has approved this study and the acknowledgement of this research is on file.

We would like to thank you in advance for taking time to participate in this survey. Please submit the completed survey by Monday, March 10, 2014. If you have questions please contact Eleanor Porter at (eporter3@mix.wvu.edu) or Dr. Harry Boone at 304293-5451 (harry.boone@mail.wvu.edu).

Sincerely,

Eleanor Porter

Graduate Student
Harry N. Boone, Jr., Ph.D. Professor and Chair 


\section{APPENDIX D:}

First Follow-Up Email 
Dear Agricultural Education Teachers,

I am conducting a graduate study on the current status of meat processing facilities in agricultural education programs in West Virginia. On March $4^{\text {th }}$ I sent you a request to participate in my study. If you have already completed my survey I ask that you please disregard this message and I thank you for your response. If you have not I am asking that you consider participating in my survey. Your responses will be greatly appreciated and will help to make my study a success. To make it easier I am including the link to my survey.

https://www.surveymonkey.com/s/ZW2SSR6

Sincerely,

Eleanor Porter

Graduate Student 
APPENDIX E:

\section{Follow-Up Cover Letter}


March 12, 2014,

Dear Agricultural Education Teachers:

On March $3^{\text {rd }}$ I sent out an email and cover letter asking for your involvement in a survey on the current status of your meat program, facilities, methods of teaching meat processing and your interest in professional development activities to improve you animal and food processing knowledge and skills. As of today I have not received your response. Your input is vital to the success of the effort. A successful meat processing facility requires a lot of effort and skills. As an agricultural education teacher, you understand the importance of training in this area. We need your input on the current status of your meat program, facilities, methods of teaching meat processing and your interest in professional development activities to improve your animal and food processing knowledge and skills.

I am Eleanor Porter, a graduate student in Agricultural and Extension Education at West Virginia University. Under the direction of my advisor, Dr. Harry N. Boone, Jr., I am conducting a research study to determine the ways meats facilities are used in the agricultural education curriculum and if West Virginia teachers with a meats facility would be interested in working in collaboration with WVU to receive more hands on training and skills in the animal processing field. The results of this study will be used to prepare a thesis to partially fulfill the requirements for a Master of Science degree in Agricultural and Extension Education. The results will provide insight to West Virginia University on the types of processional development activities that would be beneficial to agricultural educators in the state.

Participation in this research is completely voluntary and will take approximately twenty minutes of your time. All responses will be held as confidential as possible. You may skip any question that you are uncomfortable answering or may quit at any point and submit the partially completed survey. The responses of the survey will be reported in a summary format and individual responses will not be identifiable. Please answer questions honestly and to the best of your abilities. There is no penalty if you choose not to participate.

The online survey can be accessed through the following site: https://www.surveymonkey.com/s/ZW2SSR6. After completing the survey click on the "done" button. West Virginia University's Institutional Review Board (IRB) has approved this study and the acknowledgement of this research is on file.

We would like to thank you in advance for taking time to participate in this survey. Please submit the completed survey by Monday, March 21, 2014. If you have questions please contact Eleanor Porter at (eporter3@mix.wvu.edu) or Dr. Harry Boone at 304293-5451 (harry.boone@mail.wvu.edu).

Sincerely, Eleanor Porter Harry N. Boone, Jr., Ph.D. 
APPENDIX F:

Personalized Email 
Dear Mr.

If you have already filled out the survey, please disregard this message and thank you for your time. If you have not had a chance to look at it yet please consider filling it out. Information about your program would be very beneficial to my study. The final deadline is going to be Monday, March 31, 2014. I am also including the link to my survey.

https://www.surveymonkey.com/s/ZW2SSR6

Sincerely,

Eleanor Porter

Graduate Student 
APPENDIX G:

Final Email Reminder 
Dear Agricultural Education Teachers,

If you have already completed the survey on meat processing please disregard this message. The survey system has no way of tracking who has completed the survey and who has not. If you have not taken part in the study, I ask that you consider filling out the survey. The final deadline for the survey will be today Monday, March 31, 2014. Your responses will be greatly appreciated and will help to make my study a success. To make it easier I am including the link to my survey.

https://www.surveymonkey.com/s/ZW2SSR6

Sincerely,

Eleanor Porter

Graduate Student 
APPENDIX H:

Open Ended Responses 
Question 7: "Please identify the number and source of each of the following meat processing items you possess. (Only answer the choices that apply)” Responses:

2 walk in coolers purchased new. 3 chest freezers purchased new

Question 12: "How was your meats facilities funded? (Please indicate the dollar value of funding in each of the following categories)" Responses:

I'm not sure. Some was program modernization but also FEMA money was used when the building flooded in 2004

Question 13: "How is the day-to-day operation of the meat processing facility funded? (Check all that apply)”

Responses:

donations for processing

Question 14: “On average during a school year (August to August) how many animals do you process? (Please indicate the number)" Responses:

0

Custom hams cure 500 bacons 500 
Question 19: "What type(s) of animal processing classes have you taught for adult audiences over the past year? (Please indicate the course title(s))”

Responses:

Deer Processing

none

making deer bologna

Animal processing

Evening slaughter

none

Home processing

None

Question 21: "What course(s) do you teach that utilizes the meats facility? (Please indicate the course name(s))”

Responses:

Introduction to Agriculture

Animal Processing

animal processing 1

Animal processing retail

Animal processing

Introduction to Animal Processing

0183

all coarses [sic] 
Animal Processing

The science of Agriculture

Ag Science I

animal processing rtail [sic]

Animal processing plant

Advanced Principals of Agriculture

Retail meat processing

Fundamentals of animal processing

Advanced Principles of Agriculture

Ag Science II

animal processing plant

advanced agri-science

Ag natural resources 1

Ag Science II

Fundamentals of Meats Processing

Agriscience 11

science of agriculture

Aquaculture

Large Animal

intro to agriculture

Ag sci 3 and 4 
Question 25: "Please select the answer the most accurately describes your highest performance for each of the listed categories.”

Responses:

Curing and commuted sausage products

Question 29:“Would you be interested in professional development activities on the following topics offered in your region or on campus at West Virginia University? (Select all that apply)”

Responses:

smoking and other retail products bologna etc.

Question 31: “What are the non-meat processing classes that you teach? (Please provide the course names)"

Responses:

Introduction to Agriculture

Ag Mech I

none

Structures

Intro to ag

Introduction to Agriculture Mechanics, Agriculture Structures, Agriculture Repair and Maintenance

Ag \& nat res 1

greenhouse 
Ag Science II

The Science of Agriculture

Ag Mech II

fund of agri mechanics

Science of ag

Aquaculture

Ag \& nat res 1

horticulture

Large Animal

Advanced Principles of Ag

Animal Production

advanced agricultural sciences

Adv principals of ag

Fish \& Wildlife Management

Forestry

Horticulture

Horticulture

Ag Science II

leadership

Forestry

Natural Resource Conservation

Aquaculture

Fruit and Vegetable Production 
Ag Science I

Ag mech

Animal Production \& Management

Forestry

Horticulture

Leadership

Question 33: “To which of the following does your agricultural education program supply meat products? (Check all that apply)”

Responses:

We Process meat raises by local farmers fir their own personal use. [sic]

some retail sausage and pork product sales

Question 34: “How many of your students supply meat to the following places?

(Please indicate the number)"

Responses:

Local Farmers Markets

0

0

Local Farm to School Program

0

0

Local Restaurants 


\section{Local Hospitals}

0

0

\section{Other (please specify)}

Custom Customers

0

Question 35: "Which of the following value-added processing techniques do you implement? (Check all that apply)”

Responses:

Deer Bologna

Cured ham and bacon products and pork chops

Question 43: "What are your main concerns with starting a meat processing facility/program? (Check all that apply)”

Responses:

Do not have students interested

need an additional teacher

The other teacher teaches the class

We have a program- I am not the teacher...I taught animal processing for 18 years elsewhere. 
one teacher program limits classes offered

taught by other instructor

Board of Education allowing the program

Lack of administrative support

started first in WV in 1971

No room at school

middle school program

Question 46: "How do you teach meat processing information? (Check all that apply)”

Responses:

DVD and video

Question 47: "Where do you teach meat processing? (Check all that apply)" Responses:

on site at a butcher shop in Sissonville

Question 48: "What animals do you process? (Check all that apply)" Responses:

Some deer and grinding pork for sausage

Question 50: "What are your main concerns with starting a meat processing facility/program? (Check all that apply)” 
Responses:

Not enough funds 
VITA

Eleanor Porter

May 2009

July 2009-July 2010

January-May 2012

May 2012

August 2012-April 2014

August 2014
Graduated from Roane County High

School Spencer, WV 25276

West Virginia State FFA Officer

Student Teacher Taylor County Technical Center Grafton, WV 25354

Bachelor of Science in Agricultural and Extension Education West Virginia

University Morgantown, WV 26506

Graduate Teaching Assistant

AGEE 110- Microcomputer and Other

Technology Applications in Agricultural

Education

West Virginia University

Morgantown, WV 26506

Master of Science

Agricultural and Extension Education

West Virginia University

Morgantown, WV 26506 